\title{
IfIISGUC.ORG
}

"İȘ, GÜC̣" ENDÜSTRi ilLișKiLERI VE INSAN KAYNAKLARI DERGISi

"IS, GUC" INDUSTRIAL RELATIONS AND HUMAN RESOURCES JOURNAL

\section{Gelişim Kültürü Ve Lider Desteğinin Yenilikçi Davranış ve İş Performansına Etkisi: İş-Aile Çatışmasının Aracılık Rolü}

The Effect Of Development Culture and Leader Support To Innovative Behavior And Job Performance: The Mediating Role Of Work-Family Conflict

\author{
Dr.İrfan AKKOÇ, Doç.Dr. Ömer TURUNÇ, \\ Dr.Abdullah ÇALIŞKAN \\ Kara Harp Okulu
}

Ekim/October 2011, Cilt/Vol: 13, Say1/Num:4, Page: 83-114 ISSN: 1303-2860, DOI: 10.4026/1303-2860.2011.190.x

Makalenin on-line kopyasına erişmek için:

http://www.isguc.org/?p=article\&id=470\&vol=13\&num=4\&year=2011

To reach the on-line copy of article:

http://www.isguc.org/?p=article\&id=470\&vol=13\&num $=4 \& y e a r=2011$

Makale İçin İletişim/Correspondence to: 
(C) 2000- 2011

"İşGüç" Endüstri İlişkileri ve İnsan Kaynakları Dergisi

"İşGüç" Industrial Relations and Human Resources Journal

Ekim/October 2011, Cilt/Vol: 13, Say1/Num: 4

ISSN: 1303-2860, DOI: 10.4026/1303-2860.2011.190.x

Editör/Editor-in-Chief

Aşkın Keser (Uludağ University)

Editör Yardımcıları/Co-Editors

K.Ahmet Sevimli (Uludă̆ University)

Gözde Yllmaz (Marmara University)

Uygulama/Design

Yusuf Budak (Kocaeli Universtiy)

\author{
Yayın Kurulu / Publishing Committee \\ Dr.Zerrin Firat (Uludăg University) \\ Doç.Dr.Aşkın Keser (Kocaeli University) \\ Prof.Dr.Ahmet Selamoğlu (Kocaeli University) \\ Yrd.Doç.Dr.Ahmet Sevimli (Uludağ University) \\ Yrd.Doç.Dr.Abdulkadir Şenkal (Kocaeli University) \\ Yrd.Doç.Dr.Gözde Yilmaz (Kocaeli University) \\ Dr.Memet Zencirkıran (Uludağ University)
}

Uluslararası Danışma Kurulu / International Advisory Board

Prof.Dr.Ronald Burke (York University-Kanada)

Assoc.Prof.Dr.Glenn Dawes (James Cook University-Avustralya)

Prof.Dr.Jan Dul (Erasmus University-Hollanda)

Prof.Dr.Alev Efendioğlu (University of San Francisco-ABD)

Prof.Dr.Adrian Furnham (University College London-Ingiltere)

Prof.Dr.Alan Geare (University of Otago- Yeni Zellanda)

Prof.Dr. Ricky Griffin (TAMU-Texas AEM University-ABD)

Assoc. Prof. Dr. Diana Lipinskiene (Kaunos University-Litvanya)

Prof.Dr.George Manning (Northern Kentucky University-ABD)

Prof. Dr. William (L.) Murray (University of San Francisco-ABD)

Prof.Dr.Mustafa Özbilgin (University of East Anglia-UK)

Assoc. Prof. Owen Stanley (James Cook University-Avustralya)

Prof.Dr.Işık Urla Zeytinoğlu (McMaster University-Kanada)

Danışma Kurulu / National Advisory Board

Prof.Dr.Yusuf Alper (Uludağ University)

Prof.Dr.Veysel Bozkurt (Uludağ University)

Prof.Dr.Toker Dereli (Işık University)

Prof.Dr.Nihat Erdoğmuş (Kocaeli University)

Prof.Dr.Ahmet Makal (Ankara University)

Prof.Dr.Ahmet Selamoğlu (Kocaeli University)

Prof.Dr.Nadir Suğur (Anadolu University)

Prof.Dr.Nursel Telman (Maltepe University)

Prof.Dr.Cavide Uyargil (İstanbul University)

Prof.Dr.Engin Yildırım (Sakarya University)

Doç.Dr.Arzu Wasti (Sabancı University)

Dergide yayınlanan yazllardaki görüşler ve bu konudaki sorumluluk yazarlarına aittir.

Yayınlanan eserlerde yer alan tüm içerik kaynak gösterilmeden kullanılamaz.

All the opinions written in articles are under responsibilities of the outhors.

None of the contents published can't be used without being cited. 


\title{
Gelişim Kültürü Ve Lider Desteğinin Yenilikçi Davranış ve İş Performansına Etkisi: İş-Aile Çatışmasının Aracılık Rolü
}

\author{
The Effect Of Development Culture and Leader Support To Innova- \\ tive Behavior And Job Performance: \\ The Mediating Role Of Work-Family Conflict
}

\author{
Dr.İrfan AKKOÇ, Doç.Dr. Ömer TURUNÇ, Dr.Abdullah ÇALIŞKAN
}

Kara Harp Okulu

\begin{abstract}
Özet
Örgüt kültürrü ve liderlik örgütsel davranışlar üzerinde etkisi olan önemli girdi değişkenlerdendir. Son yıllarda rekabet gücünün elde edilmesinde önemli bir faktör olan yeniklikçiliğin ve iş performansının artırlmasında örgüt kültürü ve lider desteğinin rolü ve önemi giderek artmaktadır. Çalışanların yenilikçi davranışları ve iş performansının artırllmasında bir örgüt kültü̈r türü olan gelişim kültürünün ve lider desteğinin etkisini ve bu etkide iş-aile çatışmasının aracılik rolünü belirlemek bu çalışmanın temel problemini oluşturmaktadır. Savunma sektöründe yapılan bir araştırma ile çalışanların tutumları ölçülerek en uygun model belirlenmeye çalışılmıştır. Araştırma sonucunda gelişim kültürü ve lider desteğinin çalışanların yenilikçi davranışını artırdığı ve bu etkide iş-aile çatışmasının kısmi aracılık etkisi olduğu belirlenmiştir. Ayrıca gelişim kültürü ve lider desteğinin çalışanların iş performasını da artırdığı ancak bu etkide iş-aile çatışmasının aracılık etkisi olmadığı da tespit edilmiştir. Bu kapsamda yapılan gizli değiş̧kenlerle yol analiziyle uyumlu bir model kurularak yönetici ve liderlere önerilerde bulunulmuştur.
\end{abstract}

Anahtar Kelimeler: Gelişim Kültürü, Lider Desteği, Yenilikçi Davranış, İş Performansı, İş-Aile Çatışması, Aracllık etkisi, Yapısal Eşitlik Modeli.

\begin{abstract}
Organizational culture and leadership are among the important input variables having an effect on organizational behavior. In late years, Role and significance of organizational culture and leader support has climbed up in terms of improving the innovative behaviour and job performance, important factors in sustaining competitiveness. Determining the mediating role of work-family conflict in this effect development culture, which has an effect on accruing the workers' innovative behaviuor and job performance and at the same time a kind of organizational culture, and leader support constitutes the basic core of this study. With a research carried out on defence sector, a suitable model is tried to determine by measuring workers' attitudes. Results show that development culture and leader support increase the worker's innovative behaviour and this also implies that work-family conflict has a partial mediating effect. Results also show that development culture and leader support increase the job performance of workers, but in this effect work-family conflict has no mediating role. In this scope, managers and leaders are advised by establishing a model consistent with path analysis, whereby using hidden variables.
\end{abstract}

Key Words: Development Culture, Leader Support, Innovative Behavior, Job Performance, Work-Family Conflict, Mediating Effect, Structural Equation Moodeling. 


\section{Giriş}

Rekabetin yoğun olarak yaşandığı günümüzün çalışma koşulları ulusal ve uluslararası işletmelerin yenilik ve değişimlere yönelik proaktif yaklaşımlar sergilemelerini vazgeçilmez hale getirmektedir. Hem örgüt hem de kişisel düzeyde performansın sağlanmasında önemli bir faktör olan çalışanların değişimlere ve yeniliklere uyum gösteren tutum ve davranışlarının örgütte yaygınlaştırılması, desteklenmesi ve yönlendirilmesi liderler için kritik bir uğraş alanı olmuştur. Rekabet avantajlarının elde edilmesinde yeniliklerin devamli takip edilmesi ve bu yeniliklerin başarılı bir şekilde uygulanması günümüz örgütlerinin sahip olmaya çalıştığ bir yetenek olarak her geçen gün önemini artırmaktadır. Çünkü yenilikçilik; örgütsel rekabet, verimlilik ve etkinliğin sağlanmasında işletmeler için kilit role sahip bir değişkendir (Osterloh ve Frey, 2000). Çalışanların rekabetin zorunlu kıldığ 1 yenilikçilik doğrultusunda davranış sergilemesini sağlamak ve desteklemek liderlerin performanslarında vazgeçilmez bir faktör haline gelmektedir. Bir işletmede destekleyici liderler, çalışanların daha fazla güven duymalarını, etkin takım çalışması ve örgüt hedeflerine ulaşılması için daha fazla gayret göstermelerini sağlamaktadır (Podsakoff ve diğ., 1996).

Kültür işletmelerin uzun vadede rakipleri ile rekabet edebilmesini sağlayan önemli bir kaynak (Barney, 1996) ve çalışanların davranışları ve motivasyonunu etkileyen bir değişkendir (Wiener ve Vardi, 1990). Liderlerin örgüt kültürünün gelişmesinde ve değişmesinde etkili olduğuna inanılmaktadır (Kilmann, 1985). Dolayısıyla çalışanlardan; örgüt kültürü ve liderin oluşturmuş olduğu değerler çerçevesinde tutum ve davranış sergilemesi beklenmektedir. Bu kapsamda çalışanların örgüt kültürü ve liderlik tarzlarının oluşturduğu değerler doğrultusunda tutum ve davranış göstermelerinin sağlanmasında lidere önemli görev ve sorumluluklar düşmektedir.

İşin doğasında ve yapısında meydana gelen gelişmeler, çalışanların sahip olması gereken bilgi, beceri ve yeteneklerin çeşitlenerek artmasına neden olmaktadır. Bununla birlikte günümüzün rekabet koşulları nedeniyle çalışanlardan beklenen yüksek performans iş yoğunluğunu meydana getirerek iş ile ilgili problemleri artırmaktadır. Son yıllarda kadın çalışan sayısının artması ile birlikte iş-aile çatışmasını yaşayan çalışanların sayısında artış yaşanmaktadır. İş-aile çatışması örgütlerde düşük performans, tükenmişlik, devamsızlık, iş memnuniyetsizliği, işten ayrılma niyeti ve iş gücü devri gibi olumsuz sonuçların doğmasına neden olmaktadır (Cinamona ve Rich, 2005; Allen, 2001). İş-aile çatışmasının düzeyi ve sonuçlarının, iş ve aile bireyleri tarafından benimsenen toplumsal değerlere bağlı olarak değişiklik gösterdiği dolayısıyla iş-aile ilgili sorunların kültürel inanç, norm ve değerlere bağlı olduğu bilinmektedir (Eby ve diğ., 2005; Lobel, 1991; Schein, 1984). Çalışanların kendilerinden beklenen tutum, davranış ve performansı göstermesi çalıștığı işletmenin kültürel değerlerinin yaygın bir şekilde kabulü ve lider desteği ile sağlanabilir.

Bu çalışmada savunma sektöründe hem yurt içi hem de yurt dışına ürün ve hizmet sağlayan işletmelerde gelişim kültürü ve lider desteğinin; yenilikçi davranış ile iş performansı üzerindeki etkisi ve bu etkide günümüz çalışma şartlarıyla sık sık karşılaşılan iş-aile çatışmasını aracılık rolü incelenmiştir. Bu kapsamda araştırmada ele alınan değişkenlerden elde edilen verilerle gizli değişkenlerle yol analizi yapılarak yenilikçi davranış ve iş performansının artırılmasında gelişim kültürü, lider desteği ve iş-aile çatışması ile uyumlu bir model kurularak yöneticilere önerilerde bulunulmuştur.

\section{Teori ve Hipotezler}

İşletmede gelişim kültürü ve lider desteğinin yenilikçi davranış ve iş performansı üzerindeki etkisi ve bu etkide iş-aile çatışmasının aracılık rolünü belirlemek üzere tasarlanan bu ampirik araştırmada ilk olarak literatür incelenerek teorik çerçeve ortaya 
konulmuştur. Bu kapsamda gelişim kültürü, lider desteği ve çıtı değişkenler olan yenilikçi davranış ve iş performansı arasındaki ilişkiler incelenmiş ve ardından bu ilişkilerde iş-aile çatışmasının rolü ele alınarak hipotezler oluşturulmuştur.

\subsection{Yenilikçi Davranış ve İş Performansı}

Son yıllarda rekabet avantajı elde edebilmek için işletmelerde, yönetim ve üretim süreçleri başta olmak üzere mal ve hizmet üretiminde yenilik kapasitesine sahip olma gereği büyük önem kazanmıştır. Yenilik, rekabet avantaj1 sağlayan çok güçlü bir kaynaktır (Sastry,1999). Yenilik yıllarca çeşitli tanımlamaları içerecek şekilde anlam kazanarak sektörel, bölgesel, işletme ve proje düzeylerinde ve farklı biçimlerde ele alınıp araştırılmıştır. Yenilikçilik; verimlilik, etkinlik ve örgütsel rekabetin sağlanmasında işletmeler için oldukça önemli bir kavramdır (Osterloh ve Frey, 2000).

Cohen ve Levinthal (1990) bir işletmenin yeni değerleri tanıyıp farkına varması, yeniliği sağlayacak yeni bilginin alınması, işletmeye adaptasyonu ve ticari çıtılara uygulaması yenilikçilik kapasitesinin kazanılmasında önemli faktörler olduğunu ifade etmişlerdir. Yenilikçilik; yaratıcılık, öğrenme ve yeniliğin etkileşimi sonucu ortaya çıkan bir değişkendir (Fiol, 1994).

Yeniliğin açık tanımını yapmak oldukça güçtür. Çünkü Trott (1998:13) yeniliğin, örgütsel ve yönetimsel değişiklikleri içerebileceği gibi yeni ürün süreçleri, girişimler, sistemler, üretim yöntemleri, ticari düzenlemeler ve hizmetler ile ilgili de olabileceğini belirtmiştir. Van de Ven ve arkadaşları (1989) yeniliği, yeni fikirlerin işletmeye transferi ve bunların pratiğe uygulanması olarak tanımlamışlardır. Yenilik, yeni ve faydalı iş ürünlerinin, prosedürlerin ve süreçlerin bilinçli olarak uygulanması olarak ifade edilmektedir (West ve Farr, 1990).

Samuel (2000:519) yenilikçiliği “hizmet ve ürün üretiminde yeni üretim yöntemlerin uygulanması ve çalışma süreçlerinde yeni yöntemlerin geliştirilmesi" olarak tanımlamaktadır. Thomson (1965) ise yenilikçiliği, bir işletmede süreçlere, hizmetlere ve ürünlere yeni fikirlerin kabulü ve başarılı bir şekilde uygulanması olarak ifade etmektedir. Diğer bir ifade ile yenilikçilik, işletme ürünlerinde yenilikler veya yeni fikirlerin miktarı, teknolojik yenilikler ve değişikliklere uyum olarak ifade etmektedir. Buckler (1996) yenilikçiliği “işletmenin çevresinde ortaya çıkan değişimlere uyum gösterebilmesi için örgüt kültüründe değer meydana getirilmesi" olarak tanımlamaktadır (Pervaiz,1998:30). Örgütsel yenilikçilik, işletmede fayda sağlayan ve kıymete sahip yeni ürün ve hizmet meydana getirilmesidir (Woodman ve di $\breve{g}$., 1993).

Yenilikçi davranış bir çalışanın bilinçli olarak ürünler, süreçler prosedürlere ait yeni fikirleri kendi iş rolüne, iş birimine veya organizasyonuna uygulaması veya benimsemesi olarak tanımlanmaktadır (West ve Farr, 1989). Çalışanlar tarafından yapılan; yeni teknolojileri keşfetme, amaçlara ulaşmayı sağlayacak yeni yollar önerme, yeni çalışma yöntemleri uygulama ve yeni fikirleri uygulamak için kaynakları güvence altına alma ve yeni kaynaklar araştırma davranışları yenilikçi davranış örnekleridir (Yuan ve Woodman 2010).

Yenilikçi davranış ve yaratıcı davranış birbirine yakın ve ilişkili kavramlardır (Oldham ve Cummings, 1996). Yaratıcı davranış yenilikçi davranışın bir türü olarak kabul edilebilir. Çünkü yenilikçi davranış çalışanların sadece yeni fikirler üretmesi değil aynı zamanda organizasyon veya iş birimi için başkaları tarafından üretilen yeni fikirleri benimsemesini de kapsamaktadır (Woodman ve diğ., 1993). Yaratıcı davranış yeni fikirlerin üretimi ile ilgili iken yenilikçi davranış hem yeni fikir üretimi hem de bunları uygulanmasını kapsamaktadır (Zhou, 2003).

Çalışanlar, yenilikçi davranışların iş rollerine veya iş birimlerine performans veya verimlilik artışı getireceğine inandıklarında beklenen performans sonuçları pozitif olmaktadır (Ostroff ve Schmitt, 1993). Çalı- 
şanların performansları, örgüt başarımında ve arttırılmasında önemli bir etkiye sahiptir. Son yıllarda performans örgütlerde geliştirilmesi ve yönlendirilmesi gereken bir değişken olarak ortaya çıkmıștır (Murphy ve Cleveland, 1995). Bu nedenle çalışanların performanslarına etki eden değişkenlerin belirlenmesine yönelik çok sayıda araștırma yapılmıştır (Motowidlo, 2003; Campbell, 1990).

Literatürde iş performansına ait birçok tanım bulunmaktadır. Akal (2003) iş performansını, bir faaliyet sonucunda ortaya çıkan çıtıyı nicel veya nitel olarak belirleyen bir kavram olarak tanımlamaktadır. İs performansı, çalışanların ücret karşılığında sarf etmeleri gereken gayret olarak nitelenmektedir (Rousseau ve McLean, 1993). Ayrıca Kohli (1985) iş performansını, çalışanın kendine eşdeğer çalışanlara kıyasla iş ile ilgili davranış ve çıktılarının verimlilik düzeyi, Borman ve Motowidlo (1993) ise iş performansını, çalışanların icra ettikleri işe yönelik faaliyetleri ile ilgili olduğunu ifade etmişlerdir. Diğer yandan iş performansı ile yakın bir kavram olan görev performansı, iyi üretim veya hizmetin sağlanmasına katkıda bulunan (dolaylı veya doğrudan) davranışlar olarak tanımlanmaktadır (Lievens ve diğ., 2008:12).

Performans ile rekabet gücü önemli ölçüde karşılıklı etkileşim içerisinde olan değişkenlerdir. Yüksek seviyede performansa sahip çalışanlar örgüt performansının artmasını sağlamakta ve bu artış işletmeler için çok büyük öneme sahip olan rekabet gücünü yükseltmektedir (Krishnan, 2002). İş performansı örgütler açısından rekabet gücünün önemli bir göstergesidir (Wang ve Netemeyer, 2002).

Gatignon ve arkadaşları (2002) Son 30 y1lı aşan bir süredir yapılan yenilikçilik ve örgütsel çıktılar arasındaki ilişki ile ilgili yapılan araştırmalarda sonuçların belirsiz olduğunu belirtmişlerdir. Ancak, farklı bakış açısıyla yenilikçiliği ele alan araştırmacılar, örgütün performans problemlerinin tespit edilmesi ve yeniliklerin araştırılması ve be- nimsenmesinin, sorunların etkili bir şekilde çözümlenmesini ve performansın artmasını sağlayacağını bildirmişlerdir (Cyert ve March, 1992). Araştırmalar performansı geliştirmeyi taahhüt eden çalışanların yeniliğ daha kolay kabullendikleri ayrıca yeniliğin çalışanlar tarafından kısa sürede benimsenerek uygulanması örgüt performansını artırdığını göstermektedir (Tolbert ve Zucker, 1983).

Ampirik bulgular yenilikçiliğin işletmelerin rekabet avantaj1 elde etmesinde pozitif etkisinin olduğunun göstermektedir (Sorescu ve diğ., 2003). Lumpkin ve Dess (2005) 39 çalışmadan oluşan meta-analiz araştırmasında yenilikçilik ile örgüt performansı arasında ilişki bulmuştur. Deshpandé ve arkadaşları (1993) tarafından Japon firmaları arasında yapılan araştırmada yenilikçilik ile firmanın finansal performansı arasında pozitif yönlü ilişki belirlenmiştir. Çeşitli araştırmacılar tarafından yapılan çalışmalarda yenilikçilik ile örgüt performansı arasında pozitif yönlü ilişki tespit edilmiştir (Selvarajan ve diğ., 2007; Han ve diğ., 1998).

Yukarıda açıklanan çalışmalarda yenilikçilik ile örgüt performansı arasındaki ilişkiler ele alınmıştır. Literatürde yenilikçilik ile ortaya çıkacak örgüt performansı üzerinde, çalışanların önemli etkileri olduğunu gösteren çalışmalar bulunmaktadır (Zahra, 1993; Herron, 1991). Ürün ve hizmetlerde daha fazla yenilikçiliği hedefleyen örgütler, çal1şanların katılım ve güçlendirme düzeylerini yükseltmektedirler (Guthrie ve diğ., 2002). Yapılan başka bir araştırma da yenilikçiliğin çalışan yaratıcılığını ve verimliliğini artırdığı işten ayrılmaları ise azalttığı sonucuna ulasılmıstır (Urban ve diğ., 1996). Matsuo, (2009) tarafından satıs departmanlarının araştırma konusu edildiği çalışmada ise yenilikçilik ile iş performansı arasında pozitif yönlü ilişki tespit edilmiştir. Vos (2004) tarafından KOBİ'lerde yapılan araştırmada yenilikçiliğin iş performansını artırdığını göstermiştir. Ancak Evans ve arkadaşlarının (2007) satış departmanları ile ilgili yaptığı çalışmada ise yenilikçilik ile iş performansı 
arasında anlamlı bir ilişki bulgusuna rastlanılmamıştır.

Yenilikçi davranış ile iş performansı arasındaki ilişkiyi araştıran ampirik çalışmalar ve kuramdan yola çıkarak yenilikçi davranışın çalışanların iş performansına etkisini test etmek üzere geliştirilmiş hipotez aşağıda sunulmuştur.

Hipotez 1: Yenilikçi davranış çalışanların iş performansını pozitif ve anlamlı olarak etkiler.

\subsection{Gelişim Kültürü-Yenilikçi Davranış İlişkisi}

Kültür, örgütlerde başta karar alma yöntemleri olmak üzere örgüte ait birçok unsuru etkilemektedir (Shane, 1992). Kültür, örgüt üyeleri arasında olumlu davranışlar meydana getiren, paylaşılan değerler sistemidir (Wiener ve Vard1, 1990). Hofstede (1991:5) kültürü, bir zümreye mensup insanı diğerlerinden ayıran ve müşterek oluşturulmuş hafıza olarak tanımlamaktadır.

Deshpande ve Webster (1989:4) 100'den fazla örgütsel davranış, antropoloji ve sosyoloji alanında yapılan çalışmaları gözden geçirerek örgüt kültürünü; "örgütsel davranış normları ile bunları sağlayan organizasyonel fonksiyonların çalışanlar tarafından anlaşılmasını sağlayan paylaşılmış değer ve inanç yapıları" olarak tanımlamaktadır. Örgüt kültürünün amacı, çalışanın örgüt içerisinde iş veya iş dışı tutum ve davranışlarına rehberlik yapmak suretiyle, çalışanın çalışma yaşamında başarılı olmasına imkân sağlamaktır (Korte ve Chermack, 2006).

Örgüt kültürü işletmelerde çalışanların davranışlarını, inançlarını, tutumlarını ve faaliyetlerini etkilemektedir (Reeves ve Bednar, 1994). Yapılan birçok çalışmada, örgüt performansının düşük veya yüksek olmasının yaygın olarak paylaşılan kültürel değerlerin derecesine bağlı olduğu tespit edilmiştir (Denison, 1990). Örgüt kültürü ve alt kültürler işletmenin başarısını etkiliyen önemli değişkenlerdir (Chan ve diğ., 2004). Örgüt kültürünün yanısıra örgüt alt kültür- lerinin işletme ve çalışan başarısında önemli rol oynayabilceği düşüncesi örgüt davranış alanında ki araştırmaların alt kültür konusuna odaklanmasına neden olmaktadır.

Alt kültür; örgütlerde farklı anlayış, davranış ve kültürel formlara sahip çalışan gruplarını tanımlayabilmek için örgüt kültüründen belirgin farklıklar gösteren anlayış ve uygulamalar olarak tanımlanmaktadır (Trice ve Morand, 1991:1). Alt kültürleri s1nıflandırılmasında farklı yaklaşımlar bulunmaktadır. Örmeğin Wallach (1983) örgüt kültürünü; bürokratik kültür, destekleyici kültür ve yenilikçi kültür olmak üzere üç alt kültüre ayırmıştır. Quinn ve Spreitzer (1991) ise orgaizasyonel kültürü; iç odaklı olarak hiyerarşik kültür, grup kültürü dış odaklı olarak da rasyonel kültür ve gelişim kültürü olmak üzere dört alt kültürden oluştuğunu ifade etmişlerdir. Bu çalışmada Quinn ve Spreitzer (1991)'in kültür sınıflaması esas alınırak gelişim kültürüne odaklanılmıştır. Çünkü gelişim kültürü işletmelerde sürüdürebilir rekabet gücünün oluşmasında diğer alt kültürlere kıyasla daha etkili olduğu düşünülmektedir.

Gelişim kültürü, özellikle gelişme, esneklik ve diş çevre üzerine odaklanmakta ve bu odaklanmanın temel unsurları ise büyüme, kaynakların elde edilmesi, yaratıcılık ve dış çevreye uyum olarak siralanmaktadır. Gelişim kültüründe; büyüme, teşvik etme, yaratıcılık ve çeşitlilik önemli motivasyon faktörleridir. Bu kültüre sahip işletmelerde etkinlik ölçütleri; büyüme, yeni pazarların geliştirilmesi ve kaynakların elde edilmesini içermektedir (Deshpande ve Webster, 1989). Gelişim kültürü, özellikle öğrenme ile ilgili çalışanların motivasyonunu sağlayan bir örgüt alt kültürüdür (Lok ve diğ., 2005; Scott ve diğ., 2003). Gelişim kültürü gibi alt kültürler çalışanların işleriyle doğrudan ilgili ve önemli değer ve tutumları kapsamakta ve bunları güçlendirmektedir. Bu değerlerin tanımlanması ve temel oluşturulması açısından örgüt kültürüne göre daha fazla odaklanmayı ve tutarlılığı sağlamaktadır (Lok ve diğ., 2005). Ayrıca alt kültürler çalı- 
şanların mantıklı tutum ve davranış göstermesini sağlamakta (Gregory, 1983) ve çalışan tutum ve davranışlarına olumlu etkide bulunmaktadırlar (Wallach, 1983).

Son zamanlarda araştırmacılar alt kültürlerin çalışanların algılamaları ve eylemlerini şekillendiren önemli bir değişken olduğunu bildirmişlerdir (Bunch, 2007). Bazı araştırmacılar yenilikçi örgütlerin güçlü kültüre sahip olduğunu iddia ederken, bir kısmıda güçlü kültürlerin yenilikçiliği kısıtladığını öne sürmektedirler (Jaskyte, 2003). Yine bazı araştırmacılar doğru değerlerin yaygın bir şekilde paylaşıldığg 1 bir kültürün ise yaratıc1lığ1 ve yenilikçiliği etkinleştireceğini iddia etmektedirler (Flynn ve Chatman, 2001). Jaskyte tarafından (2004) 19 kar amacı gütmeyen insani hizmet organizasyonlarında yapılan araştırmada kültür ile yenilikçilik arasında negatif yönlü ilişki tespit edilmiştir. Prajogo ve McDermott (2005)'un araştırmasında bulgular, çeşitli örgüt kültür tiplerinin farklı etkileri olsa da tüm örgüt kültür tiplerinin yenilikçi davranışa etkide uyum içinde olması gerektiğini göstermektedir. Elenkov ve Manev (2009)'in yaptıkları araştırmada kültürün örgütsel yenilikçilik üzerinde düzenleyici etkisinin olduğunu belirlemişlerdir. Heracleous (2001) kültür ile ilgili değişimlerin yenilikçi davranışlarla ilişkili olduğunu ifade etmektedir. Literatürde gelişim kültürü ile yenilikçilik arasında doğrudan ilişkiyi araştıran bir çalışmaya rastlanmıştır. Bu çalışmada, Lau ve Ngo (2004) işletmelerde gelişim kültürünün yenilikçi sonuçlara pozitif etkisinin olduğunu tespit etmiştir. $\mathrm{Bu}$ kapsamda gelişim kültürünün yenilikçi davranışa etkisini test etmek üzere geliştirilmiş hipotez aşağıda sunulmuştur.

Hipotez 2: Gelişim kültürü çalışanların yenilikçi davranışını pozitif ve anlamlı olarak etkiler.

\subsection{Gelișim Kültürü Yenilikçi Davranış iliş- kisinde İş Aile Çatışmasının Aracılık Rolü}

Greenhaus ve Beutell (1985), iși-aile çatışmasını bir rol çatışması olduğunu, bir rolden diğer bir role yapılan baskı sonucunda işten aileye aileden işe karşılıklı olarak ortaya çıkan uyumsuzluk olduğunu ifade etmiștir. Kişinin is rolüne katılmasıyla birlikte aile rolü gereklerini yerine getirmek güç hale gelmektedir. Aynı şekilde çalışan bir kişinin aile rolüne katılmasıyla birlikte iș rolünün gereklerini yerine getirmek zorlaşmaktadır.

İş ve aile baskısı; sosyal ve kişisel beklentiler, değerler, inançlar ve rol ile ilgili içselleştirilmiş kişisel algılamaları yansitmaktadır (Lobel, 1991; Greenhaus ve Beutell, 1985). İş-aile çatışması ile ilgili araştırmalarda, iş-aile ve aile-iş çatışması olmak üzere iki boyutlu değişken olarak ele alınmaktadır (Frone ve diğ., 1992). İş-aile çatışması ile ilgili yapılan araştırmalar, iş-aile çatışmasının aile-iş çatışmasına kıyasla daha fazla ortaya çıktığını göstermektedir (Simon ve diğ., 2004).

Carlson ve Kacmar (2000) iş-aile çatışmasının düzeyi ve sonuçlarının, iş ve aile bireyleri tarafından benimsenen toplumsal değerlere bağlı olarak değişiklik gösterdiği ve bu değerlerin kültürel değerler olduğunu tespit etmişlerdir. Birçok araştırmacı iş-aile ilgili sorunların kültürel inanç, norm ve değerlere bağlı olduğunu ifade etmektedirler (Eby ve diğ., 2005; Lobel, 1991; Schein, 1984). Son olarak, yapılan bir araştırmada, örgüt kültürünün iş-aile çatısmasını azalttığı bulgusuna ulaşılmıştır (Thompson vd, 1999). Bu kapsamda kültürün iş aile çatışmasında belirleyici bir rolü olduğu ortaya çıkmaktadır.

Kültür ile iş-aile çatışması arasındaki ilişkiyi araştıran ampirik çalışmalar ve kuramdan yola çıkarak gelişim kültürünün iş-aile çatışmasına etkisini test etmek üzere geliştirilmiş hipotez aşağıda sunulmuştur.

Hipotez 3: Gelişim kültürü iş-aile çatışmasını negatif ve anlamlı olarak etkiler.

Günümüz çalışma yaşamında iş beklentilerinin ve yapısının değişmesi aynı zamanda kadın işgücünün artması ister istemez çalışan ve işverenleri etkilemektedir. İş-aile çatışması yaşayan çalışanların, aile ile ilgili işlerinden dolayı işlerinin sık sık kesil- 
mesi, devamsızlık ve işten ayrılma niyetlerinin artması beklenen bir durum olarak görülmektedir (Hammer, ve diğ., 1997). İş-aile çatışmasının işletme için olumsuz sonuçları, iş memnuniyetsizliği, düşük performans, devamsızlık, tükenmișlik, iș değiştirme veya işten ayrılma niyetidir (Cinamona ve Rich, 2005; Bruck, ve diğ., 2002).

$\mathrm{Bu}$ kapsamda işten kaynaklanan nedenlerle aile yaşamında sorun yaşayan çalışanların istenen düzeyde iş motivasyonuna sahip olması beklenememektedir. Stres belirli düzeylerde çalışanların işe yoğunlaşmalarıyla iş performansında artışlar meydan geldiği bilinse de yenilikçi davranışlarda artış meydana gelebileceğine ilişkin ters yönlü bir ilişki beklenmemektedir. Mor ley (2004) Avrupa da işletme başarımında aile dostu işletme anlayışının önemli olduğunu, Harker (1996) ise aile dostu iş politikalarının çalışan ve iş beklentilerini genellikle karşıladığını ifade etmişlerdir. Araştırmacılar yeniliklerin araştırılması ve benimsenmesinin problemlerin etkin bir şekilde çözülmesini sağlayacağ 1 ve iş performansı artıracağını belirtmektedirler (Cyert ve March 1992).

Yenilikçilik ve iş aile çatışması arasındaki doğrudan ilişkiyi araştıran çalışmalara rastlanmamıştır. Blau (1964) sosyal değişim teorisinden hareketle iş-aile çatışmasını azaltıcı politikalar izlenmesinin çalışan davranışlarını olumlu yönde etkileyeceği düşünülmektedir. Nitekim çatışma yaşamayan çalışanların işlerine odaklanmaları ve pozitif tutumlar sergilemeleri beklenilen bir durumdur.

Bu kapsamda iş-aile çatışmasının yenilikçi davranışa etkisini test etmek üzere geliştirilmiş hipotez aşağıda sunulmuştur.

Hipotez 4: Yenilikçi davranış iş-aile çatışmasını negatif ve anlamlı olarak etkiler.

Yapılan araştırmalarda gelişim kültürünün yenilikçi davranışla ilişkili olduğu (Lau ve Ngo, 2004) ve örgüt kültürünün iş-aile çatışmasını azalttı̆̆ 1 tespit edilmiştir (Eby ve diğ., 2005; Thompson vd, 1999; Lobel, 1991; Schein, 1984). Bu kapsamda gelişim kültü- rünün çalışanların yenilikçi davranışına etkisinde iş-aile çatışmasının aracılık rolü olabileceği düşünülmüştür. Nitekim bu iki ilişki Baron ve Kenny (1986)'nin aracılık için önerdiği ilk iki koşulu sağlamaktadır. Literatürde işletmelerdeki gelişim kültürünün çalışanların yenilikçi davranışına etkisinde iş-aile çatışmasının aracılık etkisi inceleyen araştırmaya rastlanmamıştır. Bu ihtiyaçtanda yola çıkılarak gelişim kültürünün çalışanların yenilikçi davranışına etkisinde iş-aile çatışmasının aracılık etkisini araştırmak üzere aşağıdaki hipotez oluşturulmuştur.

Hipotez 5: İşletmelerdeki gelişim kültürünün çalışanların yenilikçi davranışına etkisinde iş-aile çatışmasının aracılık etkisi vardir.

\section{4. lider Desteği İle Yenilikçi Davranış İliş- kisi}

Liderlik sürecinin anahtar konusunun etkileme olduğu bir işletmede etkilenenlerin başta çalışanlar olmak üzere örgüt yapısı ve kültürü olduğu ifade edilmektedir (Moorhead ve Griffin, 2001:360). Liderin yönetim fonksiyonlarını icra ederken sergilediği liderlik tarzı, çalışanların tutum ve davranışları üzerinde değişime yol açar. Bu değişim işletmeye ait unsurların tamamını doğrudan veya dolaylı olarak etkiler. Bu etkileşimin, liderin kişisel başarısı ve örgüt performansı üzerinde belirleyici role sahip olduğu değerlendirilmektedir.

Lider desteği, bir çalışanın yöneticisinden aldığ 1 destek ve kendisine verilen önem derecesi olarak tanımlanabilir (Netemeyer vd. 1997). Lider davranışlarının çeşitli boyutlarını açıklayan çalışmalarda, araştırmacılar liderin rolünü incelediklerinde; vizyonun benimsetilmesi, hedeflere odaklanma, destek sağlama ve geri besleme fonksiyonları ile çalışanlara destek sağladığı görülmektedir. Lider desteği çalışılmış bir çok destek kriterleri içerinde çalışanlar açısından en belirleyici olan kriterlerdendir (Ackfeldt ve Coote, 2005; Podsakoff ve diğ., 1996). 
Lider desteği, yüksek yetkinlik, çalışanlarına adil ve saygılı davranma, çift yönlü iletişim sağlama ve çalışanların bireysel katkılarının farkında olma özellikleri ile ortaya çıkmaktadır (Singh, 2000). Çalışanlar destekleyici liderlere daha fazla güvenir, etkin takım çalışması sergilerler ve örgüt hedeflerine ulaşılması için daha fazla çaba sarf etmektedirler (Podsakoff ve diğ., 1996).

Liderliğin yenilikçiliği etkileyen en önemli faktörlerden biri olduğu öne sürülmektedir (Osborne, 1998; Schin ve McClomb, 1998; Cummings ve O'Connell, 1978). Bu kapsamda son y1llarda yenilikçilik ile ilgili araştırmalarda liderliğin yenilikçiliğe olan etkisi konusuna ilgi artmaktadır (Sastry, 1999; Howell ve Avolio, 1993). Bazı araştırmacılar lider desteği ile yenilikçilik arasındaki ilişkiyi anlayabilmek için yeniliği teşvik eden liderlik tarzlarını tanımlamaya çalışmışlar ve destekleyici, katılımcı, demokratik, işbirlikçi ve vizyon sahibi olma özellikleri taşıyan liderlik tarzlarının yenilikçiliği teşvik etmede etkili olduğunu belirtmişlerdir (Schin ve McClomb, 1998; Van de Ven, 1986; Farris, 1973). Liderlerin, yeni uygulamalara destek sağlama, güç verme ve meşruluk kazandırma gibi etkilerle birlikte kaynakları yönlendirme gibi faaliyetler ile örgütsel yenilikçilik kapasitesini arttırabileceği ifade edilmektedir (Hasenfeld, 1983).

Yenilikçilik ve lider etkinliği ile ilgili yapılan araştırmalarda, lider desteğinin örgütün yenilik süreç çıktılarına pozitif yönde etkisi olduğu tespit edilmiştir (West ve diğ., 2003; Sastry, 1999; Den Hartog ve Verburg, 1997; Howell ve Avolio, 1993; Howell ve Higgins, 1990). Benzer araştırmalarda lider desteğinin; yenilikçilikle yakından ilişkili olduğunu (Howell ve Avolio, 1993) ayrıca yenilikçiliği etkileyen stratejik seçimler ve örgütsel süreçler konusunda kritik bir etkiye sahip olduğu hakkında bulgular bulunmuştur (Kisfalvi ve Pitcher, 2003). Liderlik tarzları ile yenilikçilik arasında ilişkiyi inceleyen araştırmalarda ise dönüştürücü liderlik ile yenilikçilik arasında pozitif yönde anlamlı ilişki olduğu tespit edilmiştir (Elenkov ve
Manev 2009: Jung ve diğ., 2003)

Lider desteği ile yenilikçilik arasındaki ilişkiyi araştıran ampirik çalışmalar ve kuramdan yola çıkarak lider desteğinin yenilikçi davranışa etkisini test etmek üzere geliştirilmiş hipotez aşağıda sunulmuştur.

Hipotez 6: Lider desteği çalışanlarda yenilikçi davranışı pozitif ve anlamlı olarak etkiler.

2.5. Lider desteği-Yenlikçi Davranış İlişkisinde İş-Aile Çatışmasının Aracılık Rolü

Allen (2001:417) aileyi destekleyen lideri; "çalışanların iş ve aile arasında dengeyi sağlamaya gayret gösteren çalışan isteklerine sempati ile yaklaşan ve çalışanın aile sorumlulukları ile işi uyumlaştırma çabalarına yardım eden kişi" olarak tanımlamaktadır. Lider desteği aile dostu bir yaklaşımla çalışanların isteklerini karşılamasının yanı sıra, informal yollarla çalışanın iş ve aile sorumluluklarını dengeleme taleplerine yardım ederek doğrudan iş-aile çatışmasına müdahale etmesi ile açıklanmaktadır (Allen, 2001).

Lider, çalışanların çelişkili iş ve aile ile ilgili talepleri ortaya çıktığı zaman, çalışanların aile sorumluluklarına duyarlı olduğunu gösterdiği ölçüde lider desteğinden bahsedilebilir (Warren ve Johnson, 1995). Liderler sadece aile dostu örgüt politikalarını uygulamakla kalmayıp, çalışanları iş-aile sorunları ortaya çıktığında bu sorunları yönetmek için her türlü çabayı göstermelidirler (Flye

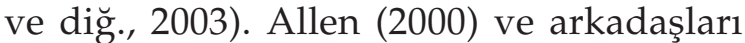
lider desteği arttıkça iş-aile çatışmasının azaldığını belirtmişlerdir.

Yazında lider desteği ile iş-aile çatışması arasındaki ilişkiyi araştıran az sayıda çalışma tespit edilmiştir. Goff ve arkadaşları (1990) tarafından okul öncesi çocuk sahibi aileler ile ilgili yapılan araştırmada aile ile ilgili sorunları görüşmeye istekli ve aile ile ilgili ortaya çıkan acil bir duruma anlayış gösteren liderlerin bulunduğu örgütlerde iş-aile çatışmasının düşük seviyede olduğu bulgusunu elde etmişlerdir. Ayrıca diğer araştırmalarda, çalışanların iş-aile taleplerini 
duyarlı olması ve onları koordine etme çabalarından oluşan lider desteğinin; iş-aile çatışmasını, devamsızlığı, tükenmişliği ve işten ayrılmaları azalttığ 1 ve örgütsel bağl1lığ1 arttığ1 sonuçlarına ulaşılmıştır. (Carlson ve Perrewe, 1999; Thomas ve Ganster, 1995; Warren ve Johnson, 1995). Frye ve Breaugh (2004) tarafında yapılan araştırmada, lider desteğinin iş-aile çatışmasını negatif ve anlamlı olarak etkilediği tespit edilmiştir.

Lider desteği ile iş-aile çatışması arasındaki ilişkiyi araştıran ampirik çalışmalar ve kuramdan yola çıkarak lider desteğinin işaile çatışmasına etkisini test etmek üzere geliştirilmiş hipotez aşağıda sunulmuştur.

Hipotez 7: Lider desteği çalışanlarda işaile çatışmasını negatif ve anlamlı olarak etkiler.

Yapılan araştırmalarda lider desteğinin yenilikçi davranış ile ilişkili olduğu (West ve diğ., 2003; Kisfalvi ve Pitcher, 2003; Howell ve Avolio, 1993) ve iş-aile çatışmasını negatif ve anlamlı olarak etkilediği tespit edilmiştir (Frye ve Breaugh 2004; Carlson ve Perrewe, 1999; Thomas ve Ganster, 1995; Warren ve Johnson, 1995). Nitekim bu iki ilişki Baron ve Kenny (1986)'nin aracılık için önerdiği ilk iki koşulu sağlamaktadır. Bu kapsamda lider desteğinin çalışanların yenilikçi davranışına etkisinde iş-aile çatışmasının aracılık rolü olabileceği düşünülmüştür. Literatürde işletmelerdeki lider desteğinin çalışanların yenilikçi davranışına etkisinde iş-aile çatışmasının aracılık etkisi inceleyen araştırmaya rastlanmamıştır. Bu ihtiyaçtanda yola çıkılarak lider desteğinin çalışanların yenilikçi davranışına etkisinde iş-aile çatışmasının aracılık etkisini araştırmak üzere aşağıdaki hipotez oluşturulmuştur.

Hipotez 8: Lider desteğinin çalışanların yenilikçi davranışına etkisinde iş-aile çatışmasının aracılık etkisi vardır.

\subsection{Gelişim Kültürü İle İş Performansı İliş- kisi}

Kültür çalışan motivasyonunun oluşturulmasında çalışanlar için önemli bir faktör- dür (Egan ve diğ., 2004). Bu kapsamda örgüt kültürü çalışanların bir takım değerler doğrultusunda davranış göstermelerini sağlamaktadır. Bu değerler örgüt çalışan ilişkisi ve çalışanların işe bakış ve uyum duygularının nasıl olması gerektiğini içerir (Schein 1985). Özellikle performans odaklı rekabet avantajı elde edilmesinde örgüt kültürünün önemli bir rol oynadığ 1 iddia edilmektedir (Scholz, 1987). Örgüt kültürü ile işletme başarısı ve performansı arasında güçlü bir ilişki olduğu bilinmektedir (Barney, 1986). Örgüt kültürü kavram olarak alt kültürleri kapsadığı halde davranış kalıpları ve uygulamalar gibi alt kültürün kendine özgü ve ayırt edici değerleri vardır (Lok ve diğ., 2005). Saffold (1988) alt kültürleri dikkate almadan örgüt kültürü düzeyinde yapılan değerlendirmelerin yetersiz olacağını öne sürmektedir.

Yapılan çalışmalarda Lok ve arkadaşları (2005) Avustralya'da çeşitli hastanelerde çalışan hemşirelerde yenilikçilik ve destekleyici alt kültür ile çalışan bağlılığı arasında pozitif yönlü, bürokratik alt kültür ile düşük düzeyde pozitif yönlü ilişki tespit etmiştir. Benzer çalışmalarda örgüt kültürü ile performans arasında yeterli ve anlamlı bir ilişki tespit etmekle birlikte farklı örgüt kültürlerinin örgüt performansını farklı şekilde etkiledikleri sonucuna ulaşılmıştır (Ogbonna ve Harris, 2000; Denison ve Mishra, 1995). Yapılan diğer araştırmalarda güven alt kültürü ile çalışanların davranışları arasında pozitif ilişki olduğu ve örgüte bağlılığ 1 arttırdığ1 (Spencer ve diğ., 2001) ancak bürokratik alt kültür uygulamaları ile çalışan davranışları arasında daha az olumlu ilişki belirlenmiştir (Duques ve Gasker, 1997). Bu çalışmalar, örgüt alt kültür çeşitleri ile hem örgüt hemde iş performansı arasında ilişki olduğunu göstermektedir.

Gelişim kültürü ile iş performansı ilişkisini araştıran çalışmalar incelendiğinde doğrudan bu ilişkiyi araştıran bir çalışmaya rastlanmamıştır. Ancak Quinn ve Spreitzer (1991) tarafından kamu sektöründe yapılan bir araştırmada gelişim kültürü ile örgüt 
performansı ve iş tatmini arasında pozitif ve güçlü bir ilişki tespit edilmiştir. Nitekim İnsan İlişkileri Teorisyenleri, iş tatmini ve iş performansını örgütsel performansı sağlayan temel bir değişken olduğunu varsaymişlardır (Likert, 1961; McGregor, 1960). Organ (1977) Sosyal Değişim Teorisi'ne göre çalışan davranışları ile örgütsel verimlilik arasındaki ilişkiyi, çalışanın iş tatmini duyması durumunda örgütün etkinliğinin artmasına yardımcı olacak şekilde davranış göstereceğini ifade ederek açıklamıştır. Ayrica Lawler ve Porter (1967) gibi Beklenti Teorisyenleri ve Locke (1970) iş tatminini iş performansının bir sonucu olduğunu ifade etmişlerdir. Yapılan çalışmalarda iş tatmini ile iş performansı arasında pozitif yönlü ve anlamlı ilişki tespit edilmiştir. (Elçi ve diğ., 2007; MacKenzie, ve diğ., 1998; Keller 1997). Bu çalışmalardan hareketle kültürün çal1şanların iş performansının artmasında belirleyici bir rolünün olduğu düşünülmektedir.

Gelişim kültürü ile iş performansını arasındaki ilişkiyi araştıran ampirik çalışmalar ve kuramdan yola çıkarak gelişim kültürünün iş performansına etkisini test etmek üzere geliştirilmiş hipotez aşağıda sunulmuştur.

Hipotez 9: Gelişim kültürü çalışanların iş performansını pozitif ve anlamlı olarak etkiler.

\subsection{Gelişim Kültürü İle İş Performansı İliş- kisinde İAÇ'nin Aracılık Rolü}

Son yıllarda işin doğasından ve iş gücünün yapısında meydana gelen değişikliklerin iş-aile çatışmasını artıracağı dolayısıyla örgütsel ve kişisel performansı etkileyecebileceği düşünülmektedir. İş-aile çatışması bir rolden gelen uyumsuzlukların diğer bir rolü baskı altına almasından kaynaklanmaktadır (Greenhaus ve Beutell 1985). Araştırmacılar iş-aile çatışmasının işten aileye ve aileden işe olmak üzere çift yönlü bir çatışma olduğunu ifade etmişlerdir (Carlson ve Frone 2003; Frone ve diğ., 1992).

İş-aile çatışmasını ele alan araştırmalar in- celendiğinde iş-aile çatışmasının; iş stresi, aile stresi, tükenmişlik, kötü madde kullanımı, iş ve yaşam tatmini, örgüt bağlılı̆̆ı, gevşek aile bağları ve iş performansı ile anlamlı bir ilişki içinde olduğu tespit edilmiştir (Eby ve diğ., 2005; Allen ve diğ., 2000; Kossek ve Ozeki, 1998; Netemeyer ve diğ., 1996). Frone ve arkadaşları (1997) tarafından yapılan araştırmada, iş-aile çatışmasının iş performansını düşürdüğü sonucuna ulaşılmıştır. Ayrıca yapılan diğger araştırmalarda, iş-aile çatışması ile çalışan bağımlılığı ve iş performansı arasında negatif yönlü bir ilişki tespit edilmiştir (Eby ve diğ., 2005; Hammer ve diğ., 2005).

İş-aile çatışması ile iş performansını arasındaki ilişkiyi araştıran ampirik çalışmalar ve kuramdan yola çıkarak iş-aile çatışmasının iş performansına etkisini test etmek üzere geliştirilmiş hipotez aşağıda sunulmuştur.

Hipotez 10: İş-aile çatışması iş performansinı negatif ve anlamlı olarak etkiler.

Yapılan araştırmalarda gelişim alt kültürü ile iş performansın arasında (Quinn ve Spreitzer, 1991), iş-aile çatışması ile iş performansı arasında ilişki olduğu (Eby ve diğ., 2005; Hammer ve diğ., 2005; Frone ve diğ., 1997) ve örgüt kültürünün iş-aile çatışması üzerinde önemli rolünün olduğu tespit edilmiştir (Eby ve diğ., 2005; Thompson ve diğ, 1999; Lobel, 1991; Schein, 1984). Nitekim bu ilişkiler Baron ve Kenny (1986)'nin aracılık için önerdiği ilk iki koşulu sağlamaktadır Bu kapsamda gelişim kültürünün çalışanların iş performansına etkisinde iş-aile çatışmasının aracılık rolü olabileceği düşünülmüştür. Literatürde işletmelerdeki gelişim kültürünün çalışanların iş performansına etkisinde işaile çatışmasının aracılık etkisi inceleyen araştırmaya rastlanmamıştır. Bu ihtiyaçtanda yola çıkılarak gelişim kültürünün çalışanların iş performansına etkisinde iş-aile çatışmasının aracılık etkisini araştırmak üzere aşağıdaki hipotez oluşturulmuştur.

Hipotez 11: İşletmelerde gelişim kültürü çalışanların iş performansına etkisinde iş- 
aile çatışmasının aracılık etkisini vardır.

\subsection{Lider Desteği İle İş Performansı İlişkisi ve Bu İlişkide İAÇ'nin Aracılık Rolï}

Liderin; kültür, strateji, ödül sistemleri gibi örgütsel özelliklere, kaynaklara (Woodman, ve diğ., 1993) veya çalışanların yaratıcı davranışlarını doğrudan etkilemesi gibi çeşitli etkilere sahip olabilmektedir (Oldham ve Cummings, 1996). Çalışanların iş performanslarının üst seviyede tutmaları özellikle organizasyonların verimlilik ve etkililiği açısindan önemlidir. Bu sebeple, yönetim alanında yapılan araştırmalarda, çalışanların performanslarını hangi değişkenlerin etkileyebileceği ve bunların ortaya çıkarılmasına yönelik çok sayıda araştırma yapılmıştır (Motowidlo, 2003; Campbell, 1990 ).

Araştırmalara göre lider desteği, çalışanlar ve örgüt açısından önemli sonuçlar meydana getirmektedir. Çalışanların stresinin azalmasını ve performansların artırmasını sağlamaktadır (Rhoades ve Eisenberger, 2002). Yapılan bir araştırmada çalışanlar tarafından algılanan lider desteğinin, örgüt hedeflerinin elde edilmesinde çalışanların gönüllü katkılarını artırdığ 1 tespit edilmiştir (Stinglhamber ve Vandenberghe, 2003).

Literatürde, lider desteği ile iş performansı arasında pozitif yönlü ve anlamlı bir ilişki bulunduğu gösteren araştırmalar bulunmaktadır (Montes ve diğ., 2005; Gagnon ve Michael 2004; Bhanthumnavin, 2003; Schaefer ve Moos, 1993). Ayrica yapilan araştırmalarda, lider desteği çalışanların sorumluluk duygusunu güçlendirerek çalışanların iş performansının artmasına yardımcı olduğu sonucuna ulaşılmıştır (Bhanthumnavin, 2003; Malatesta, 1995).

Lider desteği ile iş performansı arasındaki ilişkiyi araştıran ampirik çalışmalar ve kuramdan yola çıkarak lider desteğinin iş performansina etkisini test etmek üzere geliştirilmiş hipotez aşağıda sunulmuştur.

Hipotez 12: Lider desteği çalışanların iş performansını pozitif ve anlamlı olarak etkiler.
Yapılan araştırmalarda lider desteği ile iş performansı (Montes ve diğ., 2005; Gagnon ve Michael 2004; Bhanthumnavin, 2003; Malatesta, 1995; Schaefer ve Moos, 1993) ve işaile çatışması arasında (Frye ve Breaugh 2004; Carlson ve Perrewe, 1999; Thomas ve Ganster, 1995; Warren ve Johnson, 1995), ayrıca iş-aile çatışması ile iş performansı arasında ilişki olduğu belirlenmiştir (Eby ve diğ., 2005; Hammer ve diğ., 2005; Frone ve diğ., 1997). Nitekim bu ilişkiler Baron ve Kenny (1986)'nin aracılık için önerdiği ilk iki koşulu sağlamaktadır. Bu kapsamda lider desteğinin çalışanların iş performansına etkisinde iş-aile çatışmasının aracılık rolü olabileceği düşünülmüştür. Literatürde işletmelerdeki lider desteğinin çalışanların iş performansına etkisinde iş-aile çatışmasının aracılık etkisi inceleyen araştırmaya rastlanmamıştır. Bu ihtiyaçtanda yola çıkılarak lider desteğinin çalışanların iş performansına etkisinde iş-aile çatışmasının aracılık etkisini araştırmak üzere aşağıdaki hipotez oluşturulmuştur.

Hipotez 13: Lider desteğinin çalışanların iş performansına etkisinde iş-aile çatışmasının aracılık etkisini vardır.

\section{Araştırmanın Yöntemi}

Gelişim kültürü (GK) ve lider desteğinin (LD) yenilikçi davranış (YD) ve iş performansı (İP) üzerine etkisini ve bu etkide iş aile çatışmasının (İAÇ) aracılık rolünü belirlemeye yönelik olan bu araştırmada, öncelikle örneklem ve ölçeklere ilişkin bilgilere yer verilmiştir. Ardından örneklemlerden elde edilen veriler 1şığında oluşturulan modele ilişkin analizler yapılmıştır. Bu kapsamda öncelikle her bir değişkenin doğrulayıcı faktör analizi yapılmış ardından değişkenler arası korelasyonlar tespit edilmiştir. Yapılan hiyerarşik regresyon analizi ile hipotezler ve aracilık etkileri test edilmiştir. Ardindan en uyumlu modeli belirlemek maksadıyla yapısal eşitlik modeli (YEM) analizleri yapılmıştır. Tüm bu analizler sonucunda elde edilen bulgular mevcut literatür ile karşılaştırılarak yönetici ve 


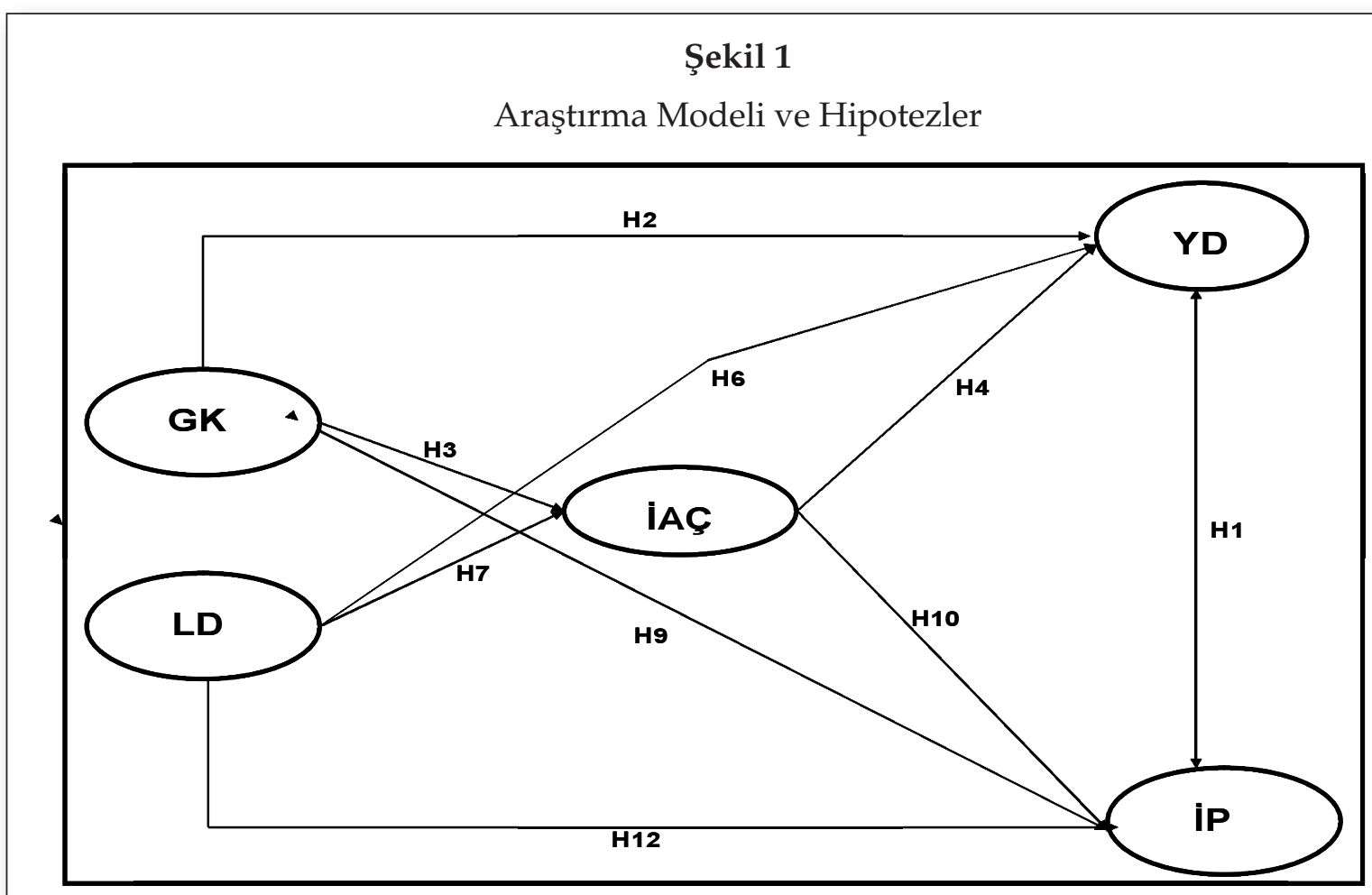

araştırmacılara önerilerde bulunulmuştur. Kuramdan ve görgül araştırmalardan yola çıkılarak oluşturulan hipotezler aşağıda sunulmuştur. Bu kapsamda yapılandırılan araştırma modeli Şekil 1'de sunulmuştur.

\subsection{Araştırmanın Örneklemi}

Araştırma evrenini Ankara'da faaliyet gösteren savunma sektörü çalışanları oluşturmaktadır. Bu örneklemde yaklaşık 2500 kişi çalışmaktadır. Ana kütleden $\% 95$ güvenilirlik sınırları içerisinde \%5'lik bir hata payı dikkate alınarak örneklem büyüklüğü 334 kişi olarak hesap edilmiştir (Sekaran, 1992:253). Bu kapsamda kümelere göre örnekleme yöntemiyle tesadüfî olarak seçilen toplam 450 kişiye anket uygulaması yapılması planlanmıştır. Gönderilen anketlerden 432'si geri dönmüş, 426's1 analiz yapmak için uygun bulunmuştur.

Araştırmaya katılanların \%77,7 kadın $(\mathrm{n}=331), \% 64^{\prime} \ddot{\mathrm{u}}(\mathrm{n}=273)$ evlidir. Çalışanların $\% 26,8(\mathrm{n}=114)$ lise, $\% 27,5(\mathrm{n}=117)$ üniversite, $\% 13,7$ ü de $(n=58)$ de lisansüstü eğitim derecesine sahiptir. Örneklemin, \%17,2 'i $(\mathrm{n}=73)$ 18-25 yaş, \%26,6's1 (n=113) 26-32 yaş, $\% 40,1$ 'i (n=171) 33-41 yaş ve \%25,2'si $(n=108)$ de 42 ve yukarı yaşlar arasındadır. Çalışanlarin \%32,1'si (n=137) 3 yıldan az, \%26,8'i (n=114) 4-7 yıl arası, \%27,5'i (n=117) 8-15 yıl arası, \%8,2 $(\mathrm{n}=35) 16-20$ y1l aras1 ve \%5,5 $(n=24)$ de 21 ve yukarı yıl iş deneyimine sahiptir.

\subsection{Araştırmanın Ölçekleri}

Gelişim kültürü (GK) ve lider desteğinin (LD) lider yenilikçi davranış (YD) ve iş performansı (IIP) üzerine etkisini ve bu etkide iş aile çatışmasının (İAÇ) aracılık rolünü belirlemeye yönelik olan bu araştırmada kullanılan ölçeklere ilişkin bilgiler aşağıda verilmektedir. Araştırmada oluşturulan modelleri ve hipotezleri test etmek amaciyla gizli değişkenlerle yol analizi yapılmıştır. Gizli değişkenlerle yol analizi yapmak için modeldeki değişkenlerin ölçülmesinde kullanılan bütün ölçüm araçlarının geçerli ve güvenilir olması gerekmektedir (Şimşek, 2007:19). Bu amaçla, araştırmada kullanılan bütün ölçeklere ilişkin yapılan geçerlilik ve 
güvenirlilik çalışmalarına ilişkin sonuçlar, her ölçekle ilgili bölümün sonunda verilmiştir.

Gelişim kültürü ölçeği (GK): İşletmelerdeki kültürün gelişim kültürü olup olmad1ğını belirlemek üzere Quinn, 1988, Quinn ve Spreitzer, 1991, Wang ve Shyu 2003 tarafından geliştirilen Tseng ve Lee (2009) tarafından kullanılan 8 maddeli ölçek kullanılmıştır. Bu ölçekteki sorular "Çalıştığım işletme verimlilik ve yaratıcılı̆̆a ă̆ırlık verir" ve "Çalıștığım işletme reformcu ve risk alan yöneticiye önem verir" şeklindedir. Ö1çekte cevaplar 5'li likert ölçeği ile alınmıştır (1=Kesinlikle katılmiyorum, 5=Kesinlikle katılıyorum).

Çalışmada Tseng ve Lee (2009)'nin çalışmasında kullanılan ölçeğin Türkçe geçerlemesi tarafımızdan yapılarak kullanılmıştır. Ölçeğin ölçek geçerleme prosedürlerine uygun olarak İngilizce-Türkçe ve Türkçe-İngilizce çevirileri alanında yetkin araştırmac1larla yapılmış pilot ve asıl örneklem üzerinde uygulanarak keşfedici faktör analizi ve doğrulayıcı faktör analizi yapılmıştır. Tseng ve Lee (2009) tarafından yapılan güvenilirlik analizleri Cronbach alfa güvenirlik katsayısı .73 olarak tespit edilmiştir.

Bu çalışmada ölçeğin yapı geçerliliğini test etmek maksadiyla öncelikle keşfedici faktör analiz yapılmıştır. Analizi sonucunda verilerin ölçeğin tek faktörlü yapısına uyum sağladığı belirlenmiştir. Devam edilen analiz sonucunda 8 maddeli ölçeğin faktör yüklerinin .67 ile .74 arasında olduğu tespit edilmiştir. Ölçeğin KMO analiz sonucu .96 ve Barlett testi anlamlı $(\mathrm{p}=.000)$ olarak tespit edilmiştir. $\mathrm{Bu}$ analizlerin ardından Amos paket programı ile doğrulayıcı faktör analizi yapılmıştır. Faktör analizi sonucunda verilerin ölçeğin tek faktörlü yapısına uyum sağladığ1 ve faktör yüklerinin .79 ile .82 arasında olduğu tespit edilmiştir. Ölçeğin uyum iyiliği değerleri diğer ölçeklerinki ile birlikte Tablo 1'de sunulmuştur. Yapılan güvenirlik analizi sonucunda ölçeğin toplam Cronbach alfa güvenirlik katsayısı .93 olarak bulunmuştur.
Lider Desteği Ölçeği: Çalışanların algıladıkları lider desteğini ölçmek üzere Netemeyer arkadaşları (1997) tarafından geliştirilen 5 soruluk ölçek kullanılmıştır. Toplam 5 ifadeden oluşan bu ölçekte sorular "Çalıştı̆̆ım işletmede bizlere yöneticimiz tarafindan destek verilmektedir" ve "Yöneticim işler zorlaştı̆̆ı durumlarda bile güvenilirdir" gibidir. Ölçekte cevaplar 5'li likert ölçeği ile alınmıştır (1=Kesinlikle katılmıyorum, $5=$ Kesinlikle katılıyorum).

Bu çalışmada Ackfeldt ve Coote (2005)'in çalışmasında kullanılan ölçeğin Türkçe geçerlemesi tarafımızdan yapılarak kullanılmiştır. Ölçeğin ölçek geçerleme prosedürlerine uygun olarak İngilizceTürkçe ve Türkçe-İngilizce çevirileri alanında yetkin araştırmacılarla yapılmış pilot ve asıl örneklem üzerinde uygulanarak keşfedici faktör analizi ve doğrulayıcı faktör analizi yapılmıştır. Ackfeldt ve Coote (2005) tarafından yapılan güvenilirlik analizleri Cronbach alfa güvenirlik katsayısı .89 olarak tespit edilmiştir.

Çalışmada ölçeğin yapı geçerliliğini test etmek maksadıyla öncelikle keşfedici faktör analiz yapılmıştır. Bu analizi sonucunda verilerin ölçeğin tek faktörlü yapısına uyum sağladığı belirlenmiştir. Analiz sonucunda 5 maddeli ölçeğin faktör yüklerinin .74 ile .76 arasında olduğu tespit edilmiştir. Ölçeğin KMO analiz sonucu .90 ve Barlett testi anlamlı $(\mathrm{p}=.000)$ olarak tespit edilmiştir. Bu analizlerin ardından Amos 6.0 paket programı ile doğrulayıcı faktör analizi yapılmıştır. Faktör analizi sonucunda verilerin ölçeğin tek faktörlü yapısına uyum sağladığ1 ve faktör yüklerinin .82 ile .83 arasında olduğu tespit edilmiştir. Yapılan güvenirlik analizi sonucunda ölçeğin toplam Cronbach alfa güvenirlik katsayısı .92 olarak bulunmuştur.

İş-Aile Yaşam Çatışması Ölçeği: Çalışanların iş-aile yaşam çatışması düzeylerini ölçmek üzere Netemeyer ve arkadaşları (1996) tarafından geliştirilen iş-aile yaşam çatışması ölçeği kullanılmıştır. Ölçek, çal1şanların iş yaşamından kaynaklanan iş-aile 
çatışması ve aile yaşamından kaynaklanan aile-iş çatışması düzeylerini ölçmeyi amaçlayan iki alt boyuttan oluşmaktadır. Bu çalışmada işten aileye yansıyan çatışma düzeyini belirlemeye yönelik olan iş-aile çatışması boyutu kullanılmıştır. Ölçek 5 maddeden oluşmakta olup sorular "İş sorumluluklarım aile ve ev yaşantımı olumsuz olarak etkiliyor" ve "İşimin aldı ̆̆̆ zaman aileme karşı sorumluluklarımı yerine getirmemi zorlaştırıyor" şeklindedir. Cevaplar 5'li likert ölçeği ile alınmıştır (1=Kesinlikle katılmiyorum, 5=Kesinlikle katıliyorum). Netemeyer ve arkadaşları (1996) tarafından yapılan güvenilirlik analizleri sonucunda, işaile çatışması boyutlarının Cronbach alfa güvenilirlik katsayısı .88 olarak tespit edilmiştir. Ölçek Türkçe'ye Efeoğlu (2006) tarafından çevrilmiştir. Yapılan güvenilirlik analizleri sonucunda maddelerin Cronbach alfa güvenilirlik katsayısının .83 olduğu belirlenmiştir.

Ölçeğin yapı geçerliliğini test etmek maksadıyla doğrulayıcı faktör analizi yapılmıştır. Faktör analizi sonucunda verilerin ölçeğin iki faktörlü yapısına uyum sağladığ ve faktör yüklerinin .78-.83 arasında olduğu tespit edilmiştir. Yapılan güvenilirlik analizi sonucunda iş-aile çatışması güvenilirliği .90 olarak bulunmuştur. Ölçeğin KMO analiz sonucu .89 ve Barlett testi anlamlı $(\mathrm{p}=.000)$ olarak tespit edilmiştir.

İş Performansı Ölçeği: Çalışanların iş performansının ölçülmesinde; önce Kirkman ve Rosen (1999), daha sonra ise, Sigler ve Pearson (2000) tarafından kullanılan iş performansı ölçeği kullanılmıștır. Dört sorudan oluşan ölçekte sorular "İşimde göstermiş olduğum performans düzeyim yüksektir" ve "İş hedeflerime fazlasıyla ulaşırım" şeklindedir. Ölçeğin güvenirlik katsayısı her iki çalışmada da .70'in üstündedir. Türkiye'de Çöl (2008) tarafından akademisyenler üzerinde uygulanan ölçeğin güvenirlik katsayısı $\quad .82$ olarak tespit edilmiştir. Araştırmada cevaplar 5’li likert ölçeği ile alınmıştır (1=Kesinlikle katılmiyorum, 5=Kesinlikle katıliyorum).
Yapılan doğrulayıcı faktör analizi sonucunda ölçeğin tek faktörlü yapıya sahip olduğu, faktör yüklerinin .80-.88 arasinda değiştiği belirlenmiştir. Ölçeğin Cronbach alfa güvenirlik katsayısı .87 olarak tespit edilmiştir. Ölçeğin KMO analiz sonucu .81 ve Barlett testi anlaml1 $(\mathrm{p}=.000)$ olarak tespit edilmiştir.

Yenilikçi Davranış Ölçeği: Çalışanların yenilikçi davranışa eğiliminin ölçülmesinde Scott ve Bruce. (1994) tarafından kullanılan ölçek kullanılmıștır. Altı sorudan oluşan ölçekte sorular "Yeni teknolojiler, süreçler, teknikler araștırım ve fikirler üretirim" ve "Yenilikçiyim" şeklindedir. Ölçeğin güvenirlik katsayısı .89 olarak tespit edilmiştir ve ölçekte cevaplar 5'li likert ölçeği ile alınmıştır (1=Kesinlikle katılmiyorum, 5=Kesinlikle katiliyorum).

Bu çalışmada bu ölçeğin Türkçe geçerlemesi tarafımızdan yapılarak kullanılmıştır. Ölçeğin ölçek geçerleme prosedürlerine uygun olarak İngilizce-Türkçe ve Türkçe-İngilizce çevirileri alanında yetkin araştırmacılarla yapılmış pilot ve asıl örneklem üzerinde uygulanarak keşfedici faktör analizi ve doğrulayıcı faktör analizi yapılmıştır.

Çalışmada ölçeğin yapı geçerliliğini test etmek maksadıyla öncelikle keşfedici faktör analiz yapılmıștır. Analizi sonucunda verilerin ölçeğin tek faktörlü yapısına uyum sağladığ 16 maddeli ölçeğin faktör yüklerinin .83 ile .86 arasında olduğu tespit edilmiştir. Ölçeğin KMO analiz sonucu .89 ve Barlett testi anlamlı $(p=.000)$ olarak tespit edilmiştir. Bu analizlerin ardindan Amos paket programı ile doğrulayıc faktör analizi yapilmıştır. Faktör analizi sonucunda verilerin ölçeğin tek faktörlü yapısına uyum sağladığ1 ve faktör yüklerinin .59 ile .80 arasında olduğu tespit edilmiştir. Ölçeğin uyum iyiliği değerleri diğer ölçeklerinki ile birlikte Tablo 1 'de sunulmuştur. Yapılan güvenirlik analizi sonucunda ölçeğin toplam Cronbach alfa güvenirlik katsayısı .86 olarak bulunmuştur. 
Tablo 1

Doğrulayıcı Faktör Analizi Sonucunda Ölçeklerin Uyum İyiliği Değerleri

\begin{tabular}{|l|c|c|c|c|c|c|c|}
\hline \multicolumn{1}{|c|}{ Değişkenler } & $\begin{array}{c}\text { CMIN/ } \\
\text { DF }<5\end{array}$ & $\begin{array}{c}\text { GFI } \\
>.85\end{array}$ & $\begin{array}{c}\text { AGFI } \\
>.80\end{array}$ & $\begin{array}{c}\text { CFI } \\
>.90\end{array}$ & $\begin{array}{c}\text { NFI } \\
>.90\end{array}$ & $\begin{array}{c}\text { TLI } \\
>.90\end{array}$ & $\begin{array}{c}\text { RMSEA } \\
<.08\end{array}$ \\
\hline 1. Gelişsim Kültürü (GK) & 1,4 &, 99 &, 99 &, 99 &, 99 &, 99 &, 01 \\
\hline 2. Lider Desteği (LD) & 1,8 &, 99 &, 99 &, 99 &, 99 &, 99 &, 01 \\
\hline 3. İş-Aile Çatışması (İAÇ) & 1,8 &, 99 &, 98 &, 99 &, 99 &, 99 &, 03 \\
\hline 4. Yenilikçi Davranış (YD) & 2,5 &, 99 &, 96 &, 99 &, 99 &, 98 &, 05 \\
\hline 5. İş Performansı (İP) & 1,17 &, 99 &, 98 &, 99 &, 99 &, 99 &, 01 \\
\hline
\end{tabular}

\subsection{Bulgular}

Araştırma sonucunda elde edilen verilere SPSS ve Amos programinda analizler yapılmiştır. Bu kapsamda, ilk aşamada katılımc1ların algıladıkları lider desteğ $i$, iş aile çatışması, iş performansı ve yenilikçi davranışına ilişkin elde edilen verilerin ortalamaları, standart sapmaları ve aralarındaki korelasyonlara bakılmıştır. Analizin ikinci yapilan hiyerarşik regresyon analizi ile aracılık etkisi araştırılmıştır. Ardından yapısal eşitlik modeli ile kurulan modele ilişkin yol analizi yapılmıştır. Analiz sonucunda elde edilen ortalamalar, standart sapmalar ve korelasyon değerleri tablo 2 'de verilmektedir.

Tablo 2‘de de görüldüğü gibi araştırmaya konu edilen tüm bağımlı ve bağımsız değişkenler arasında anlamlı ilişkiler bulunmak- tadır. Özellikle LD-GK, İP-GK ve İP-LD arasındaki yüksek düzeydeki ilişki dikkat çekmektedir. Bu nedenle değişkenler arasında önemli etkiler öngörülebilmektedir.

Analiz kapsamında modelde çoklu doğrusal bağlantı sorunu olup olmadığını belirlemek maksadiyla doğrudaşlığa (collinearity) da bakılmıştır. Elde edilen tolerans ve VIF değerleri bağımsız değişkenler arası çoklu bağlantı olmadığını doğrulayan sonuçlar vermiştir (Tolerans $>$ $.2, \mathrm{VIF}<10)$.

Çalışanların iş aile çatışmasının; lider desteğinin yenilikçi davranışa ve işperformansina etkisinde ve gelişim kültürünün yenilikçi davranışa ve iş performansına etkisinde aracılık etkisini açıklamak amacıyla, Baron ve Kenny (1986) tarafından önerilen

\section{Tablo 2}

Verilere İlişkin Ortalama, Standart Sapma ve Korelasyon Değerleri

\begin{tabular}{|c|c|c|c|c|c|c|c|}
\hline & Ort. & S.S. & $\mathbf{1}$ & $\mathbf{2}$ & $\mathbf{3}$ & $\mathbf{4}$ & $\mathbf{5}$ \\
\hline 1.GK & 3,04 & 1,05 & $(, 93)$ & & & & \\
\hline 2. LD & 3,08 & 1.08 &, $87^{* *}$ & $(, 92)$ & & & \\
\hline 3. İAÇ & 2,58 & 1,01 & $-59^{* *}$ &,$- 56^{* *}$ & $(, 89)$ & & \\
\hline 4. YD & 3,37 &, 91 &, $74^{* *}$ &, $69^{* *}$ &,$- 72^{* *}$ & $(, 85)$ & \\
\hline 5. IP & 3,13 & 1,06 &, $84^{* *}$ &, $84^{* *}$ &,$- 48^{* *}$ &, $76^{* *}$ & $(, 90)$ \\
\hline
\end{tabular}

${ }^{*} \mathrm{p}<.05{ }^{* *} \mathrm{p}<.01$ Not: Ölçeklere ait güvenirlilik katsayıları parantez içinde verilmiştir 
üç aşamalı regresyon analizi yapılmıştır. $\mathrm{Bu}$ yönteme göre, aracılık etkisinden söz edilebilmesi için üç şartın var olması gerekmektedir:

(1) Bağımsız değişkenin aracı değişken üzerinde bir etkisi olmalıdır.

(2) Bağımsız değişken bağımlı değişken üzerinde etkili olmalıdır.

(3) Aracı değişken ikinci adımdaki regresyon analizine dâhil edildiğinde, bağımsız değişkenin bağımlı değişken üzerindeki regresyon katsayısı düşerken, aracı değişkenin de bağımlı değișkenler (YD ve İP) üzerinde anlamlı bir etkisi olmalıdır. Bu kapsamda çalışanların İAÇ düzeyinin aracılık rolünü belirlemek amacıyla, değişkenler arasındaki ilişkiler hiyerarşik regresyon analizleri arac1lığ 1 ile incelenmiştir. Aracılık testine ilişkin bulgular Tablo 3'de verilmektedir.

Aracılık testi kapsamında ilk aşamada bağımsız değişken gelişim kültürü ile yenilikçi davranış ve iş performansı arasındaki ilișkilere bakılmıştır. Bu aşamanın ilk adımında GK'nın YD'yi $(\beta=.74, \mathrm{P}<.001)$ ve GK'nın İP'yi $(\beta=.84, P<.001)$ anlamlı olarak etkilediği görülmüştür. Bu bulgular Hipotez 2 ve 9'un desteklendiğini göstermektedir. İkinci adımda GK'nın aracılığı araştırılan İAÇ'ye olan etkisi araştırılmıştır. Analiz sonucunda GK'nın İAÇ'yi anlamlı olarak etkilediği $(\beta=-.59, \mathrm{P}<.001)$ tespit edilmiştir. $\mathrm{Bu}$ bulguya göre Hipotez 3 desteklenmektedir. $\mathrm{Bu}$ adımda aracılığ 1 araştırılan İAÇ'nin YD ve İP'ye olan etkilerine de bakılarak rapor edilmiştir. İAÇ hem YD'yi $(\beta=-.71, \mathrm{P}<.001)$ hem de İP'yi $(\beta=-.78, P<.001)$ anlamlı olarak etkilemektedir. Bu bulgulara göre Hipotez 10 ve 4 desteklenmektedir. Bu aşamanın son adımında ise GK ve aracılığı araştırılan İAÇ birlikte analize sokulmuş ve YD ve İP üzerindeki etkilerine bakılmıştır. Bu analiz sonucunda GK'nın İAÇ ile birlikte analize sokulmasıyla YD' üzerindeki etkisi devam etmiş ve azalmış $(\beta=.48, \mathrm{P}<.001)$, İAÇ'nin de YD üzerindeki etkisi devam etmiştir ( = .43, $\mathrm{P}<.001)$. Bu bulgu GK'nın YD'ye etkisinde İAÇ’nin kısmi aracılık rolü üstlendiğini göstermektedir. Elde edilen bu bulgu Sobel testi ile sınanmış ve desteklenmiştir $\left(\mathrm{z}=14,8^{* * *}\right)$. Bu bulguya göre Hipotez 5 desteklenmektedir. Bunun tersi olarak bu adımda GK'nın yine İAÇ ile birlikte analize sokulmasıyla İP üzerindeki etkisi devam etmiş ve $\operatorname{artmiş~}(\beta=.84, \mathrm{P}<.001)$, İAÇ'nin ise İP üzerindeki etkisi ortadan kalkmıştır ( $\beta=$ .02, P>.05). Bu bulgu GK'nın İP'ye etkisinde İAÇ'nin aracılık rolü olmadığını göstermektedir. Bu bulgu ile aracılık hipotezi olan hipotez 11 destek bulmamıştır.

Aracılık testinin ikinci aşamasında diğer bağımsız değişken lider desteği ile yenilikçi davranış ve iş performansı arasındaki ilişkilere bakılmıştır. Bu aşamanın ilk adımında LD'nin YD'yi $\beta=.69, \mathrm{P}<.001)$ ve LD'nin IIP'yi $(=.84, \mathrm{P}<.001)$ anlamlı olarak etkilediği görülmüştür. Bu bulgular Hipotez 6 ve 12'nin desteklendiğini göstermektedir. İkinci adımda LD'nin aracılığ 1 araştırılan İAÇ'ye olan etkisi araştırılmıştır. Analiz sonucunda LD'nin İAÇ'yi anlamlı olarak etkilediği $(\beta=$ $.56, \mathrm{P}<.001)$ tespit edilmiştir. Bu bulgu Hipotez 7 nin desteklendiğini göstermektedir. Bu aşamanın son adımında ise LD ve arac1lığı araştırılan İAÇ birlikte analize sokulmuş ve YD ve İP üzerindeki etkilerine bakılmıştır. Bu analiz sonucunda LD'nin İAÇ ile birlikte analize sokulmasıyla YD'üzerindeki etkisi devam etmiş ve azalmış $(\beta=.42$, $\mathrm{P}<.001)$, İAÇ'nin de YD üzerindeki etkisi devam etmiştir $(\beta=-.48, \mathrm{P}<.001)$. Bu bulgu LD'nin YD'ye etkisinde İAÇ'nin kısmi arac1lık rolü üstlendiğini göstermektedir. Elde edilen bu bulgu Sobel testi ile sınanmış ve desteklenmiştir $\left(\mathrm{z}=14,1^{* * *}\right)$. Bu bulgu ile aracllık hipotezi olan hipotez 8 destek bulmuştur. Bunun tersi olarak bu adımda LD'nin yine İAÇ ile birlikte analize sokulmasıyla İP üzerindeki etkisi devam etmiş ve azalmış $(\beta=.83, \mathrm{P}<.001)$, İAÇ'nin ise İP üzerindeki etkisi ortadan kalkmıştır $(\beta=.01, P>.05)$. Bu bulgu LD'nin İP'ye etkisinde İAÇ'nin arac1lık rolü olmadığını göstermektedir. Bu bulgu ile aracılık hipotezi olan hipotez 13 destek bulmamıştır. 
Tablo 3

Aracılık Testi Sonuçları

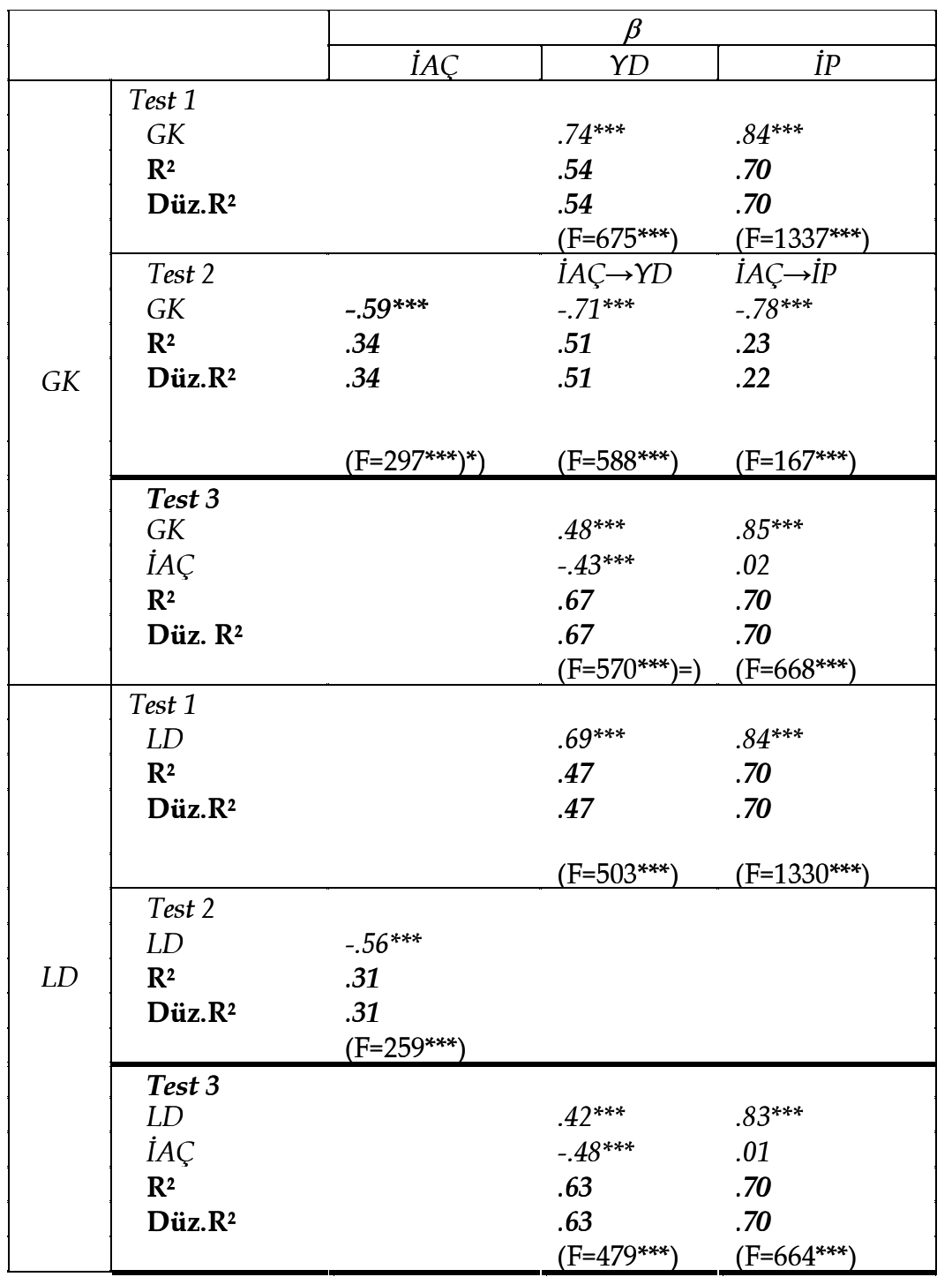

${ }^{*} \mathrm{p}<.05^{* *} \mathrm{p}<.01^{* * *} \mathrm{p}<.001$

Yapılan analizlerle değişkenlerin ayrı ayrı ve hiyerarşik olarak bağımlı değişkenler üzerindeki etkileri ortaya konulmuş olmasına rağmen modelin toplu olarak geçerliliği ortaya konulamamıştır. Bu maksatla, bu analizlerin ardından araștırmaya konu edilen değişkenlerin hangi model kapsamında daha uyumlu olduğu sorusunun cevaplanabilmesi için araştırma modeli kapsamında yapısal eşitlik modeli analizi yapılmıştır. Bu analiz kapsamında gizli değişkenlerle yol analizleri ile değişkenlerin en uyumlu olduğu model aranmıştır.

Çalışanların yenilikçi davranışına ve iş performansına İAÇ, gelişim kültürü ve lider desteğinin etkilerini belirlemeye ilişkin kurulan yapısal eşitlik modelinin analiz sonuçları Şekil 2'de verilmektedir. Modelin uyum indeksleri incelendiğinde; GFI (Goodness of fit index) değerinin .87, AGFI (Adjusted goodness of fit index) değerinin .84, CFI (Comperative fit index-Karşılaştırmalı uyum 
indeksi) değerinin .95, TLI (Tucher- Lewis indeksi) değerinin .96, NFI (Normlanmış uyum iyiliği indeksi) .95, CMIN/DF değerinin 3,6 ve RMSEA (Root mean square error of approximation-Kök ortalama kare yaklaşım hatas1) değerinin de 0.06 olduğu tespit edilmiştir. Bir modelin kabul edilmesi için RMSEA değerinin 0.08 altında olması gerekir (Şimsek, 2007). Elde edilen bu değerler kapsamında verinin iyi uyum iyiliği değerleri ve kabul edilebilir değerler verdiği için oluşturulan yapısal eşitlik modelinin kabul edilebilir olduğunu söylenebilir (Joreskog ve Sorbom, 1993; Kline, 1998).

Hiyerarşik regresyon analiz sonuçlarına göre tüm bağımsız değişkenlerin aracı ve bağımlı değişkenleri etkilemesine rağmen tüm değişkenlerin toplu olarak yol analizi ile incelendiği yapısal eşitlik analizi sonuçlarına göre lider desteğinin İAÇ üzerinde anlamlı bir etkisi olmadığ1 ve uyumlu modelin başlangıç modelinden farklılaştığ görülmüştür.

\section{Tartışma ve Sonuç}

$\mathrm{Bu}$ araştırmada işletmede algılanan geli- şim kültürü ve lider desteğinin çalışanların yenilikçi davranış ve iş performansı üzerindeki etkisi ve bu etkide iş-aile çatışmasının aracılık rolü incelenmiştir.

Bu maksatla Ankara'da faaliyet gösteren savunma sektörü çalışanları üzerinde uygulamalı bir araştırma yapılmıştır. Bu araştırma ile analize dâhil edilen değişkenlerin yenilikçi davranış ve iş performansı üzerindeki etkileri hiyerarşik regresyon analizi ve yapısal eşitlik modeli yardımıyla açıklanmaya çalışılmıştır. Yapılan araştırma ile savunma sektörüne ilişkin gelişim kültürü ve lider desteği ilişkisine yönelik açıklayıcı bulgular elde edilmiştir.

Analiz sonuçları incelendiğinde diş odaklı örgüt kültür türlerinden gelişim kültürünün yenilikçi davranış ile ilişkili olduğu ve yenilikçi davranışı pozitif ve anlamlı olarak artırdığ 1 belirlenmiştir. Bu bulgu benzer araştırmalar ile uyumludur (Lau ve Ngo 2004). Yaratıcılık ve esnekliğe odaklanan bu örgüt alt kültür çeşitinin yenilikçi davranışı beklenildiği gibi olumlu yönde etkilemiştir.

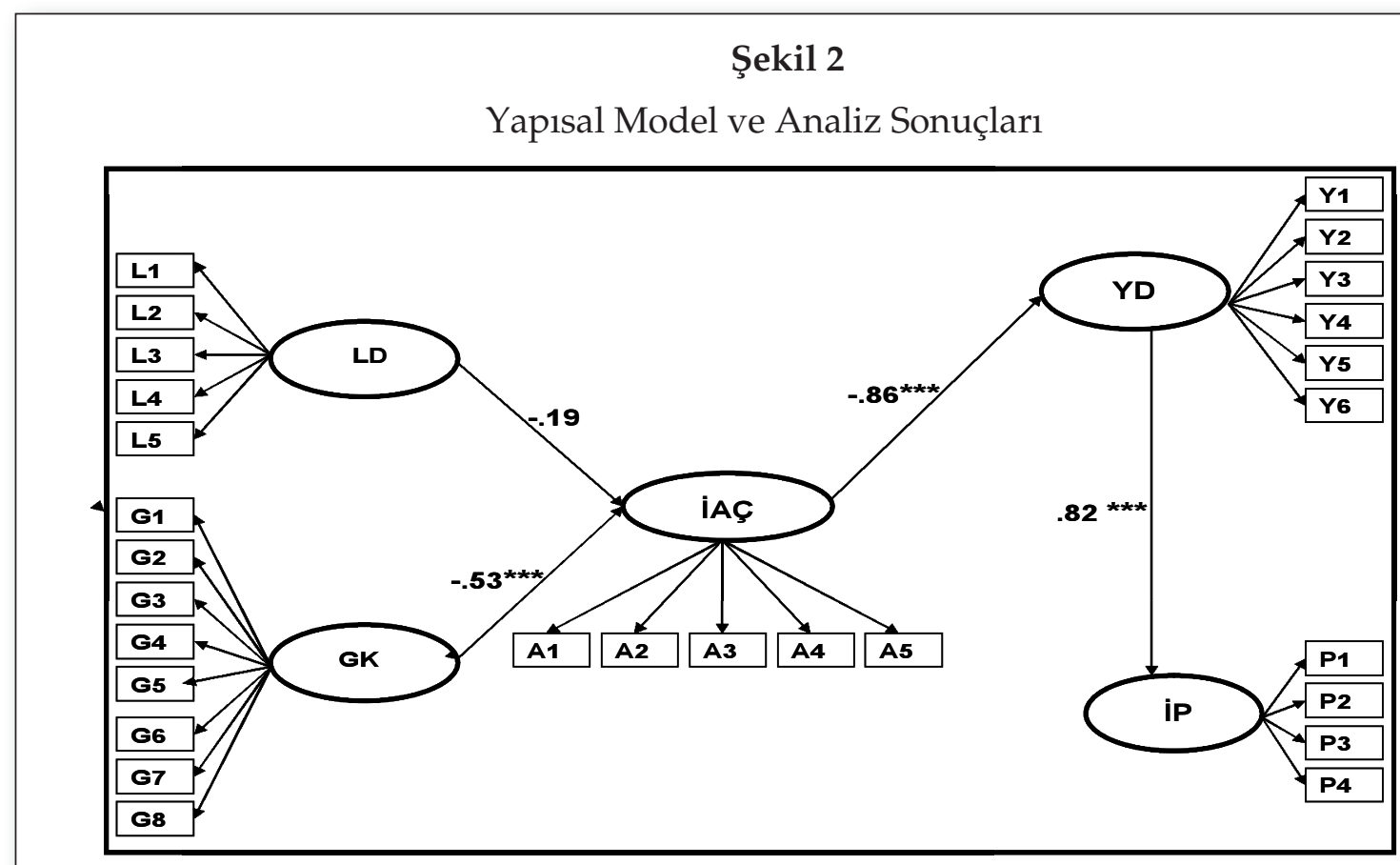

${ }^{*} \mathrm{pA} .05^{* *} \mathrm{p}<.01{ }^{* * *} \mathrm{p}<.001$ 
Gelişim kültürü iş-aile çatışmasının etkileşimi negatif ve anlamlı olarak etkilediği tespit edilmiştir. $\mathrm{Bu}$ bulgu da benzer araştırmalar ile uyumludur (Eby ve diğ., 2005; Schein, 1984; Lobel, 1991; Carlson and Kacmar 2000; Thompson vd, 1999). Gelişim kültürünün büyüme, teşvik etme, yaratıcılık ve çeşitlilik gibi önemli motivasyon faktörleri içermesinin çalışanın iş ile ilgili sorunlarını azalttığı böylece işten aileye yasıyan problemlerin azalması ile birlikte iş-aile çatışma düzeyini beklenildiği gibi azaltmıștır. Gelişim kültürü iş performansı ile ilişkili olduğu iş performansını pozitif ve anlamlı olarak artırdığ 1 belirlenmiştir. Bu bulgu araştırmacıların diğer alt kültür çalışmaları ile elde ettikleri bulgular (Lok, 2005; Spencer ve diğ., 2001; Denisin ve Mishra, 1995; Ogbonna ve Harris, 2000) ve gelişim kültürünün performansı pozitif yönde etkilemesi bulgusu (Quinn ve Spreitzer 1991) ile uyumludur.

Lider desteğinin yenilikçi davranış ile ilişkili olduğu yenilikçi davranışı pozitif ve anlamlı olarak artırdığı belirlenmiştir. Bu bulgu benzer araştırmalar ile uyumludur (West, ve diğ., 2003; Howell ve Avolio, 1993; Kisfalvi ve Pitcher, 2003; Elenkov ve Manev 2009; Jung ve diğ., 2003). Lider desteğinin işaile çatışması ile ilişkili olduğu iş-aile çatışmasını negatif ve anlamlı olarak etkilediği belirlenmiştir. Bu bulgu da benzer araştırmalar ile uyumludur (Thomas ve Ganster, 1995; Carlson ve Perrewe, 1999; Warren ve Johnson, 1995; Frye ve Breaugh 2004). Lider desteğinin iş performansı ile ilişkili olduğu iş performansını pozitif ve anlamlı olarak artırdığ 1 belirlenmiştir. Bu bulgu da benzer araştırmalar ile uyumludur (Montes ve diğ., 2005; Gagnon ve Michael 2004; Schaefer ve Moos, 1993; Bhanthumnavin, 2003; Malatesta, 1995).

İş aile çatışması yenilikçi davranış ile ilişkili olduğu ve yenilikçi davranışı negatif ve anlamlı olarak etkilediği belirlenmiştir. Bu bulgu araştırmacıların beklentileri ile uyumludur (Blau, 1964; Cyert ve March 1992). İşaile çatışması iş performansı ile ilişkili olduğ $\mathrm{u}$ iş performansını negatif ve anlamlı olarak etkilediği belirlenmiştir. Bu bulgu benzer araștırmalar ile uyumludur (Frone ve diğ.,1997; Eby ve diğ., 2005; Hammer ve diğ., 2005). Yenilikçi davranış iş performansı ile ilişkili olduğu iş performansını pozitif ve anlamlı olarak etkilediği belirlenmiştir. Bu bulgu da benzer araştırmalar ile uyumludur (Urban, ve diğ., 1996; Matsuo, 2009; Vos, 2004).

Gelişim kültürü ve lider desteğinin çal1şan davranışlarına etkisinin olduğu, bu etkinin bazı değişkenler aracılığı ile de çıktı değişkenlere yansıyabildiği düşünülmüştür. Bu noktadan hareketle gelişim kültürü ve lider desteğinin yenilikçi davranış ve iş performansına olan etkisinin iş-aile çatışmasının aracılık rolü araştırılmıştır. Bu kapsamda elde edilen bulgulardan gelişim kültürünün yenilikçi davranışa etkisinde iş-aile çatışmasının kısmi aracılık rolü olduğu ancak gelişim kültürünün iş performansına etkisinde iş-aile çatışmasının aracılık rolü olmadığ 1 bulgusuna ulaşılmıştır. Ayrıca elde edilen bulgulardan lider desteğinin yenilikçi davranışa etkisinde iş-aile çatışmasının kısmi aracılık rolü olduğu ancak lider desteğinin iş performansına etkisinde iş-aile çatışmasının herhangi bir aracılık rolü olmadığ ${ }_{1}$ belirlenmiştir.

Çalışanların yenilikçi davranış sergileyebilmesi; yaratıcılığa, yeniliğe ve değişimlere çok yoğun bir şekilde odaklanması ve lider desteğini zorunlu kılmaktadır. Dolayısıyla çalışanların bu davranışlarını etkisizleştirecek iş-aile çatışması gibi çeşitli örgütsel davranışların örgüt yaşamında yer almamasını gerektirmektedir. Bu nedenle gelişim kültürünün ve lider desteğinin yenilikçi davranışa etkisinde iş-aile çatışmasının kısmi aracılık rolünün olduğu düşünülmektedir. Ayrıca algılanan gelişim kültürü ve lider desteği çalışanların motivasyonunu arttıran çok önemli değişkenlerdir. Bu güçlü motivasyonun iş performansına etkisinde, iş-aile çatışmasının aracılık rolünün etkisizleşmesine yol açtı̆g 1 değerlendirilmektedir.

Sonuç olarak, işletmelerde algılanan hem 
gelişim kültürü hem de lider desteğinin çalışanların yenilikçi davranış ve iş performansının artırılmasında önemli etkisi olan değişkenler olduğu ortaya konulmuştur. Günümüzün çalıșma yaşamında rekabet için vazgeçilmez olan çalışanların yüksek düzeyde yenilikçi davranışa sahip olmalarının sadece gelişim kültürü ve lider desteği oluşturmakla değil bunlarla birlikte iș-aile çatışması gibi aracı değerlerin de etkilemesiyle olabileceğinin ortaya konulması bu çalışmanın önemli bir sonucudur. Ayrıca gelişim kültürü ve lider desteğinin iş performansını artırmasında iş-aile çatışmasının aracılık rolünün olmadı̆̆ının ortaya konulması bu çalışmanın diğer bir önemli sonucudur. $\mathrm{Bu}$ kapsamda yönetici ve işletmelere gelişim kültürü ve lider desteği oluşturmaları durumunda iş performansının artacağı aynı zamanda çalışanların iş-aile çatışmalarını azaltacak tedbirler alarak çalışanları yenilikçi davranışa yönlendirebilecekleri önerisinde bulunulabilir. Bu araştırmada iki ayrı meteoloji kullanılarak ele alınan beş değişken yapisal eşitlik modeli ile modellenmeye çalışılmıştır. Yapılan yol analizi ile araştırma modeliyle uyumlu bir model oluşturularak araştırmacılara ve yöneticilere model alternatifi sunulmuştur. Modelin farklı iki yöntemle analiz edilmesi bu araștırmanın ayrıcalığı olduğu düşünülmektedir. Yapısal eşitlik analizi sonuçlarına göre lider desteğinin iş-aile çatışması üzerinde anlamlı bir etkisinin olmadiğ 1 ve uyumlu modelin başlangıç modelinden farklılaştı̆̆ı görülmüştür. Büyüme, teşvik etme, yaratıcılık ve çeşitlilik gibi motivasyon faktörlerini içeren gelişim kültürü ile ürünler, süreçler ve prosedürlere ait yeni fikirlere odaklanan yenilikçi davranış değişkenlerinin çalışanların lider desteğine olan ihtiyacını ortadan kaldirması nedeniyle uyumlu modelim farkl1laştığ1 düşünülmektedir. Araştırma sonunda sunulan yapısal eșitlik modeli çerçevesinde teşkil edilecek yapıların işletmelerde rekabet kapasitesini artırabileceği değerlendirilmektedir.

$\mathrm{Bu}$ araştırmanın bazı sınırlılıkları bulunmaktadır. Araştırmanın sadece savunma sektöründe yapılmış olması araştırmanın önemli bir kısıtıdır. Bu nedenle diğer sektörlerde yapılacak araștırmalardan farklı sonuçlar ortaya çıkabilir. Ayrıca bu alanda yapılacak benzer araștırmaların yaygın bir eğilime işaret edecek destekleyici veya açıklayıcı bilgiler verebileceği düşünülmektedir. Araștırman bir diğger kısıtıda araștırmanın boylamsal olmamasıdır. Farklı adımlarla elde edilecek bulguların daha açıklayacı olabileceği değerlendirilmektedir.

Gelecekte bu alanda araştırma yapacak akademisyenlere yenilikçi davranışların ve iş performansının artırılmasında diğer örgüt alt kültürlerinin ve liderlik tarzlarının etkilerini ve bu etkide iş-aile çatışmasının rolünü araştırmaları önerilebilir. 


\section{Kaynakça}

Ackfeldt, A.L. ve Coote, L. V. (2005), A Study of Organizational Citizenship Behaviors in A Retail Setting, Journal of Business Research, 58, s. 151-159.

Akal, Z. (2003), Performans Kavramları ve Performans Yönetimi, MPM, Ankara.

Allen, T. D. (2001), Family-Supportive Environments: The Role of Organizational Perceptions, Journal of Vocational Behavior, 58:3, s. 414-435.

Allen, T.D., Herst, D.E.L., Bruck, C.S., ve Sutton, M. (2000), Consequences Associated With Work-To-Family Conflict: A Review and Agenda For Future Research, Journal of Occupational Health Psychology, 5, s. 278-308.

Barney, J. B. (1986), Strategic Factor Markets: Expectations, Luck and Business Strategy, Management Science, 32, s. 12311241.

Barney, J. B. (1996), Organizational Culture: Can It be a Source of Sustained Competitive Advantage?, Academy of Management Review, 11, s. 656-65.

Baron, R. M. ve Kenny, D. A. (1986), The Moderator Mediator Variable Distinction in Social Psychological Research: Conceptual, Strategic, and Statistical Considerations. Journal of Personality and Social Psychology, 51, s. 1173-1182.

Bhanthumnavin, D. (2003), Perceived Social Support From Supervisor and Group Members' Psychological and Situational Characteristics As Predictors of Subordinate Performance in Thai Work Units, Human Resource Development Quarterly, 14, s. 79-97.

Blau, P. (1964), Exchange and Power in Social Life, New York: Wiley.
Borman, W. C. ve Motowiidlo, S. J. (1993), Expanding The Criterion Domain to Include Elements of Contextual Performance, (der.), Schmitt, N. ve Borman, W.C. Personnel Selection in Organizations, San Francisco, Ca: Jossey-Bass, s. 71-98.

Bruck, C. S., Allen, T. D. ve Spector, P. (2002), The Relation Between Work-Family Conflict and Job Satisfaction: A Finergrained Analysis. Journal of Vocational Behavior, 60, s. 336-353.

Bunch, K. J. (2007), Training Failure as A Consequence of Organizational Culture, Human Resource Development Review, 6:2, s. 142-163.

Campbell, J. P. (1990), Modeling The Performance Prediction Problem in Industrial and Organizational Psychology (der.) Dunnette, M. D. ve Hough, L. M. 2nd ed. Handbook of Industrial and Organizational Psychology, 1. Palo Alto: Consulting Psychologists Press, Inc., s. 687-732.

Carlson, D. ve Perrewe P. (1999), The Role of Social Support in the Stressor-Strain Relationship: An Examination of WorkFamily Conflict. Journal of Management, 25:5, s. 13-40.

Carlson, D., ve Frone M. (2003), Relation of Behavioral and Psychological Involvement to a New Four-Factor Conceptualization of Work-Family Interference, Journal of Business and Psychology, $17: 4$, s. 515-535.

Carlson, D.S., Kacmar, K.M., ve Williams, L.J. (2000), Construction and Initial Validation of A Multidimensional Measure of Work-Family Conflict, Journal of Vocational Behavior, 56, s. 249-276. 
Chan, L. L. M., Shaffer, M. A., ve Snape, E. (2004), In Research of Sustained Competitive Advantage: The Impact Of Organizational Culture, Competitive Strategy And Human Resource Management Practices On Firm Performance, International Journal of Human Resource Management, 15:1, s. 17-35.

Cinamona R. G. ve Rich, Y. (2005), Work-Family Conflict Among Female Teachers, Teaching and Teacher Education, 21, s. 365-378.

Cohen, W.M. ve Levinthal, D.A. (1990), Absorptive Capacity: A New Perspective on Learning And İnnovative, Administrative Science Quarterly, 35, s. 128-152.

Cummings, L.L. ve O'Connell, M.J. (1978), Organizational Innovation, Journal of Business Research, 6, s. 33-50.

Cyert, R. M., ve March, J. G. (1992), A Behavioral Theory of the Firm (2nd ed.), Cambridge, England: Blackwell Business.

Çöl, G. (2008), Algılanan Güçlendirmenin İşgören Performansı Üzerine Etkileri, Doğuş Üniversitesi Dergisi, 9:1, s. 35-46.

Den Hartog, D. N. ve Verburg, R. M. (1997), Charisma And Rhetoric: Communicative Techniques of International Business Leaders, Leadership Quarterly, 8:4, s. 355-391.

Denison, D. R. (1990), Corporate Culture and Organizational Effectiveness, New York: Wiley.

Denison, D. R. ve Mishra, A. K. (1995), Toward A Theory of Organizational Culture and Effectiveness. Organization Science, 6:2, s. 204-223.
Deshpandé, R, Farley J. U., ve Webster, Jr. F. E. (1993), Corporate Culture, Customer Orientation, and Innovativeness in Japanese Firms: A Quadrad Analysis. Journal of Marketing, 57:1, s. 23-37.

Deshpande, R. ve Webster, Jr. F. E. (1989), Organizational Culture and Marketing: Defining the Research Agenda, Journal of Marketing, 53, s. 3-15.

Duques, R., ve Gasker, P. (1997), The Big Organization of The Future. In F. Hesselbein (ed.), Organization of The Future (s. 67-88), San Francisco: Jossey-Bass.

Eby, L.T., Casper, W.J., Lockwood, A., Bordeaux, C., ve Brinley, A. (2005), Work and family research in IO/OB: Content analysis and review of the literature (1980-2002), Journal of Vocational Behavior, 66, s. 124-197.

Efeoğlu, İ. E. (2006), İş-Aile Yaşam Çatışmasının İş Stresi, İş Doyumu ve Örgütsel Bağlılık Üzerindeki Etkileri: İlaç Sektöründe Bir Araştırma, Yayınlanmamıș Doktora Tezi, Çukurova Üniversitesi, Adana.

Egan, T. M., Yang, B. ve Bartlett, K. R. (2004), The Effects of Organizational Learning Culture Onmotivation to Transfer Learning and Turnover Intention, Human Resource Development Quarterly, 5(3), s. $279-301$.

Elci, M., Kıtapcı H. ve Ertürk A. (2007), Effects of Quality Culture And Corporate Ethical Values on Employee Work Attitudes And Job Performance in Turkey: An Integrative Approach, Total Quality Management, 18:3, s. 285-302.

Elenkov, D. S. ve Manev I. M. (2009), Senior Expatriate Leadership's Effects on Innovation and the Role of Cultural Intelligence, Journal of World Business, 44, s. 357-369. 
Elenkov, D.S. ve Manev I. M. (2005), Top Management Leadership and Influence on Innovation: The Role of Sociocultural Context, Journal of Management, 31:3, s. 381-402.

Evans, K. R., Timothy D. Landry, Po-Chien Li, ve Zou S. (2007), How Sales Psychological Climate Perceptions, Journal of the Academy of Marketing Science, $35: 3$, s. $445-459$.

Farris, G. F. (1973), The Technical Supervisor: Beyond the Peter Principle. Technical Review, 75, s. 25-39.

Fiol, C. M. (1994). Consensus, Diversity, and Learning in Organizations, Organization Science, 5, s. 403-420.

Flye, L., Agars M., ve Kottke J. (2003), Organizational Approaches to Work-Family Conflict: Testing an Integrative Model, Discussion Paper, Society of Industrial Organizational Psychology.

Flynn, F. J. ve Chatman, J. A. (2001). Strong Cultures and Innovation: Oxymoron or Opportunity? In C. L. Cooper, S. Cartwright, ve P. C. Earley (ed.), International Encyclopedia of Social and Behavioral Sciences. New York: Wiley.

Foley, S., Hang-Yue N. ve Lui S. (2005), The Effects Ofwork Stressors, Perceived Organizational Support, and Gender on Work-Family Conflict in Hong Kong, Asia Pacific Journal of Management, 22, s. 237-256.

Frone, M.R., Russell, M. ve Cooper, M.L. (1992). Antecedents and Outcomes of Work-Family Conflict: Testing A Model of The Work-Family Interface, Journal of Applied Psychology, 77, s. 65-78.

Frone, M. R., Yardley J. K. ve Markel K. S. (1997), Developing and Testing An Integrative Model of The Work-Family Interface, Journal of Vocational Behavior, 50:2, s. 145-167.
Frye, N. K. ve Breaugh, J. A. (2004). FamilyFriendly Policies, Supervisor Support, Work-Family Conflict, Family-Work Conflict, and Satisfaction: A Test of A Conceptual Model, Journal of Business and Psychology, 19:2. s. 197-220.

Gagnon, M. A. ve Michael J. H. (2004), Outcomes of Perceived Supervisor Support For Wood Production Employees, Forest Prod. Journal, 5412, s. 172-177.

Gatignon, H., Tushman, M., Smith, W. ve Anderson, P. (2002), A Structural Approach to Assessing Innovation: Construct Development of Innovation Locus, Type, and Characteristics, Management Science, 48:9, s. 1103-1122.

Goff, S. J., Mount, M. K., ve Jamison, R. L. (1990), Employer Supported Child Care, Work-Family Conflict, and Absenteeism: A Field Study, Personnel Psychology, 43, s. 793-809.

Greenhaus, J. H., ve Beutell, N. (1985), Sources of Conflict Between Work and Family Roles, Academy of Management Review, 10:1, s. 76-88.

Gregory, K. (1983), Native-View Paradigm, Multiple Culture and Culture Conflicts in Organizations, Administrative Science Quarterly, 28, s. 359-376.

Guthrie, J.P., Spell, C.S. ve Nyamori, R.O. (2002), Correlates and Consequences of High Involvement Work Practices: The Role of Competitive Strategy. International Journal of Human Resources Management, 13:1, s. 183-97.

Hammer, L. B., Neal, M. B., Newson, J. T., Brockwood, K. J., ve Colton, C. L. (2005), A Longitudinal Study of The Effects of Dualearner Couples' Utilization of Family-Friendly Workplace Supports on Work and Family Outcomes, Journal of Applied Psychology, 90, s. 799-810. 
Hammer, L., Allen B. E. ve Grigsby, T. D. (1997). Work-Family Conxict in DualEarner Couples: Within Individual and Crossover Effects of Work and Family, Journal of Vocational Behavior, 50, s. 185-203.

Han, Jin K., Namwoon Kim, ve Srivastava R. K. (1998), Market Orientation and Organizational Performance: Is Innovation a Missing Link?, Journal of Marketing, 62:4, s. 30-45.

Harker, L. (1996), The Family Friendly Employer in Europe, In S. Lewis, \& J. Lewis (ed.), The Work Family Challenge.

Hasenfeld, Y. (1983), Human Service Organizations, Upper Saddle River, N.J.: Prentice Hall.

Heracleous, L. (2001), An Ethnographic Study of Culture in The Context of Organizational Change. Journal of Applied Behavioral Science, 37, s. 426-446.

Herron, L. (1991), Cultivating Corporate Entrepreneurs, Human Resource Planning, 15:4. s. 3-14.

Hofstede, G. (1991), Organization and Cultures: Software of the Mind, London: McGraw-Hill.

Hofstede, G. (1998). Identifying Organizational Subcultures: An Empirical Approach, Journal of Management Studies, $35: 1$, s. $1-12$.

Howell, J. M. ve Avolio, B. J. (1993), Transformational Leadership, Transactional Leadership, Locus of Control, and Support For Innovations: Key Predictors of Consolidated-Business-Unit Performance, Journal of Applied Psychology, 78:6, s. 891-903.

Howell, J. M. ve Higgins, C. A. (1990), Champions of Technological Innovation, Administrative Science Quarterly,
35:2, s. 317-341.

Jaskyte K., (2004), Transformational Leadership, Organizational Culture, and Innovativeness in Nonprofit Organizations, Nonprofit Management \& Leadership, 15.2, s. 153-168.

Jaskyte, K. (2003), Organizational Culture and Innovation in Nonprofit Human Service Organizations, Dissertation Abstracts International, 63:10.

Joreskog, K. G. ve Sorbom D. (1993), Lisrel 8: Structural Equation Modeling With The SIMPLIS Command Language, Chicago, IL: Scientific International Software.

Jung, D. L, Chow, C, ve Wu, C. (2003), The Role of Transformational Leadership in Enhancing Organizational Innovation: Hypotheses and Some Preliminary Findings, Leadership Quarterly, 14, s. 523544.

Keller, R. T. (1997), Job Involvement And Organizational Commitment As Longitudinal Predictors of Job Performance: A Study of Scientists And Engineers, Journal of Applied Psvchology, 82, s. 539545.

Kilmann, R. H. (1985), Five Steps to Close the Culture Gap, in Kilmann, R. H., Saxton, M., Serpa, R. (eds) Gaining Control of the Corporate Culture, Jossey-Bass, San Francisco.

Kirkman, B. L. Rosen, B. (1999), Beyond SelfManagement: Antecedents and Consequences of Team Empowerment, Academy of Management Journal, 42:1, s. $58-74$.

Kisfalvi, V. ve Pitcher, P. (2003), Doing What Feels Right: The Influence of CEO Character and Emotions on Top Management Team Dynamics, Journal of Management Inquiry, 12, s. 42-66. 
Kline, R. B. (1998), Principles and Practice of Structural Equation Modeling. New York: The Guilford Press.

Kohli, A. (1985), Some Unexplored Supervisory Behaviors and Their Influence on Salespeople's Role Clarity, Specific Self Esteem, Job Satisfaction and Motivation, Journal of Marketing Research, 22, s. $424-433$.

Korte, R. F. ve Chermack, T. J. (2006), Changing Organizational Culture with Scenario Planning, Futures, s. 1-12.

Kossek, E.E. ve Ozeki, C. (1998), Work-Family Conflict, Policies, and The Job-Life Satisfaction Relationship: A Review and Directions for Organizational BehaviorHuman Resources Research, Journal of Applied Psychology, 83, s. 139-149.

Krishnan, V. R. (2002), Transformational Leadership and Value System Congruence, International Journal of ValueBased Management, 15:1, s. 19-33.

Lau, C.M. ve Ngo H. Y. (2004), The HR System, Organizational Culture, and Product Innovation, International Business Review, 13, s. 685-703.

Lawler, E. E., III. ve Porter, L. W. (1967), The Effect of Performance on Job Satisfaction, Industrial Relations, 7, s. 20-28.

Lievens, F. Conway J. M. ve De Corte, W. (2008), The Relative Importance of Task, Citizenship and Counterproductive Performance to Job Performance Ratings: Do Rater Source and TeamBased Culture Matter?, Journal of Occupational and Organizational Psychology, 81, s. 11-27.

Likert, R. (1961), New Patterns of Management, New York: Mcgraw-Hill.
Lobel, S. A. (1991), Allocation of Investment in Work and Family Roles: Alternative Theories and Implications for Research, Academy of Management Review, 16, s. 507-521.

Locke, E. A. (1970), Job Satisfaction and Job Performance: A Theoretical Analysis, Organizational Behavior and Human Performance, 5, s. 484-500.

Lok, P., Westwood, R. ve Crawford, J. (2005), Perceptions of Organizational Subculture and Their Significance for Organizational Commitment, Applied Psychology, 54:4, s. 490-514.

Lumpkin, G. G. ve Dess, G. T. (2005), The Role of Entrepreneurial Orientation in Stimulating Effective Corporate Entrepreneurship, Academy of Management Executive, 19:1, s. 147-156.

MacKenzie, S. B. Podsakoff, P. M. ve Ahearne, M. (1998), Some Possible Antecedents of In-Role And Extra-Role Salesperson Performance, Journal of Marketing, 62, s. 87-98.

Malatesta, R. M. (1995), Understanding the Dynamics of Organizational and Supervisory Commitment Using A Social Exchange Framework, Unpublished Doctoral Dissertation, Wayne State University.

Mathieu, J. E. ve Zajac, D. M. (1990), A Review and Meta-Analysis of The Antecedents, Correlates, and Consequences of Organizational Commitment, Psychological Bulletin, 108:2, s. 171-194.

Matsuo, M. (2009), The Influence of Sales Management Control on Innovativeness of Sales Departments, Journal of Personal Selling \& Sales Management, 29:4, s. 321-331. 
McGregor, D. (1960), The Human Side of Enterprise, New York: McGraw Hill.

Montes, J. L., Moreno, A. R. ve Morales, V. G. (2005), Influence of Support Leadership and Teamwork Cohesion on Organizational Learning, Innovation and Performance: An Empirical Examination, Technovation, 25, s. 1159-1172.

Moorhead, G. ve Griffin R. W. (2001), Organizational Behavior Managing People and Organizations, Sixth Edition, Hougton Mifflin Company, Boston New York.

Morley, M. J. (2004), Contemporary Debates in European Human Resource Management: Context and Content, Human Resource Management Review, 14, s. 353-364.

Motowidlo, S. J. (2003), Job Performance. Inw. Borman, Ilgen, D. ve Klimoski, R., Handbook of Psychology: Industrial and Organizational Psychology, 12, Hoboken, Nj: John Wiley and Sons, s. 3953.

Murphy, K. R. ve J. N. Cleveland, (1995), Understanding Performance Appraisal, Social, Organizational and Goal Based Perspectives, Sage Pub. London.

Netemeyer, R. G, Boles J. S, Mckee D. O. ve Mcmurrian, R. (1997), An Investigation into The Antecedents of Organizational Citizenship Behaviors in A Personal Selling Context, Journal of Marketing, 613 , s. $85-98$.

Netemeyer, R. G., Boles, J. S. ve McMurrian, R. (1996), Development and Validation of Work-Family Conflict Scales, Journal of Applied Psychology, 81, s. 400-410.

Ogbonna, E. ve Harris, L. C. (2000), Leadership Style, Organizational Culture and Performance. Empirical Evidence From UK Companies, International Journal of Human Resource Management, 11:4, s. 766-788.
Oldham, G. R. ve Cummings, A. (1996), Employee Creativity: Personal and Contextual Factors at Work, Academy of Management Journal, 39:3, s. 607-634.

Organ, D. W. (1977), A Reappraisal and Reinterpretation of The Satisfaction-Causes-Performance Hypothesis, Academy of Management Review, 2, s. 46-53.

Osborne, S. P. (1998), Naming the Beast: Defining and Classifying Service Innovations in Social Policy, Human Relations, 51, s. 1133-1155.

Osterloh, M. ve Frey, B. (2000), Motivation, Knowledge Transfer, and Organizational Forms, Organization Science, 11 , s. $538-550$.

Ostroff, C. ve Schmitt, N. (1993), Configurations of Organizational Effectiveness and Efficiency, Academy of Management Journal, 36, s. 1345-1361.

Pervaiz, A. (1998), Culture and Climate for Innovation, European Journal of Innovation Management, 1:1, s. 30-31.

Podsakoff, P. M., Mackenzie S. B. ve Bommer W. H. (1996), Transformational Leader Behaviors and Substitutes For Leadership As Determinants of Employee Satisfaction, Commitment, Trust, and Organizational Citizenship Behaviors, Journal of Management, 222, s. 259298.

Prajogo, D. I. ve Mcdermott, C. M. (2005), The Relationship Between Total Quality Management Practices and Organizational Culture, International Journal of Operations and Production Management, 25:11, s. 1101-1122.

Quinn, R. E. (1988), Beyond Rational Management: Mastering the Paradoxesn and Competing Demands of High Performance, San Francisco: Jossey-Bass. 
Quinn, R. E. ve Spreitzer, G. E. (1991), The Psychometrics of The Competing Values Culture Instrument and An Analysis of The Impact of Organizational Culture on Quality of Life, Research on Organizational Change and Development, 5, s. 115-142.

Reeves, C. ve Bednar, D. (1994), Defining Quality: Alternatives and Implications, Academy of Management Review, 19:3, s. $419-445$.

Rhoades, L. ve Eisenberger, R. (2002), Perceived Organizational Support: A Review of The Literature, Journal of Applied Psychology, 87, s. 698-714.

Rousseau, D. M. ve Mclean P. J. (1993), The Contracts of Individuals and Organizations. (ed.), Cummings, L. L. ve Staw, B. M., Research in Organizational Behavior, 15, s. 1-43.

Saffold, G. S. (1988), Culture Traits, Strength, and Organizational Performance: Moving Beyond "Strong" Culture. Academy of Management Review, 13, s. 546-558.

Samuel, C. C. (2000), Modern Management Diversity, Quality, Ethics \& the Global Environment, Prentice Hall International Inc., London.

Sastry, M. A. (1999), Managing Strategic Innovation and Change, Administrative Science Quarterly, 44:2, s. 420-422.

Schaefer, J. A. ve Moos, R. H. (1993), Relationship, Task, and System Stressors in The Health Care Workplace, Journal of Community and Applied Social Psychology, 3, s. 285-298.

Schein, E. H. (1984), Culture As an Environmental Context for Careers, Journal of Occupational Behavior, 5, s. 71-81.
Schein, E. H. (1985), Organizational Culture and Leadership, San Francisco: JosseyBass.

Schin, J. ve McClomb, G. E. (1998), Top Executive Leadership and Organizational Innovation: An Investigation of Nonprofit Human Service Organizations, SocialWork Administration, 22:3, s. 121.

Scholz, C. (1987), Corporate Culture and Strategy-The Problem of Strategic Fit, Long Range Planning, 25, s. 3-16.

Scott, S. G., ve Bruce, R. A. (1994), Determinants of Innovative Behavior: A Path Model of Individual Innovation in The Workplace, Academy of Management Journal, 37:3, s. 580-607.

Scott, T., Mannion, R., Marshall, M., ve Davies, H. (2003), Does Organizational Culture Influence Healthcare Performance? A Review of The Evidence. Journal of Health Services Research and Policy, 8:2, s. 105-117.

Sekaran, U. (1992), Research Methods For Business, Canada: John Wiley ve Sons, Inc.

Selvarajan, T.T., Ramamoorthy, N., Flood, P. C., Guthrie, J. P., MacCurtain, S. ve Liu W. (2007), The Role of Human Capital Philosophy in Promoting Firm Innovativeness and Performance: Test of a Causal Model, International Journal of Human Resource Management, 18:8, s. 1456-1470.

Shane, S. A. (1992), Why Do Some Societies Invent More Than Others?, Journal of Business Venturing, 7:1, s. 29-46.

Sigler, T. H. ve Pearson, C. M. (2000), Creating An Empowering Culture: Examining The Relationship Between Organizational Culture and Perceptions of Empowerment, Journal of Quality Management, 5, s. 27-52. 
Simon, M., Kummerling, A. ve Hasselhorn, H. M. (2004), Work Home Conflict Among The European Nursing Profession, International Journal of Occupational Environment Health, 10, s. 384-391.

Singh, J. (2000), Performance Productivity and Quality of Frontline Employees In Service Organizations, Journal of Marketing, 642, s. 15-34.

Sorescu, A.B., Chandy, R.K. ve Prabhu, J.C. (2003), Sources and Financial Consequences of Radical Innovation: Insights from Pharmaceuticals, Journal of Marketing, 67, s. 82-102.

Spencer-Laschinger, H. K., Finegan, J. ve Shamian, J. (2001), The Impact of Workplace Empowerment, Organizational Trust on Staff Nurses Work Satisfaction and Organizational Commitment, Health Care Management Review, 26:3, s. 7-23.

Stinglhamber, F. ve Vandenberghe C. (2003), Organizations and Supervisors As Sources of Support and Targets of Commitment: A Longitudinal Study, Journal of Organizational Behavior, 24, s. 251270.

Şimşek, Ö. F. (2007), Yapısal Eşitlik Modellemesine Giriș: Temel İlkeler ve Lisrel Uygulamaları, Ekinoks, Ankara.

Thomas, L. T. ve Ganster, D. C. (1995), Impact of Family-Supportive Work Variables on Work-Family Conflict and Strain: A Control Perspective, Journal of Applied Psychology, 80, s. 6-15.

Thompson, C. A., Beauvads, L. L. ve Lyness, K. S. (1999), When Work-Family Benefits Are Not Enough: The Influenceof Work-Family Culture on Benefit Utilization, Organizational Attachment, and Work-Family Conflict Journal of Vocational Behavior, 54, s. 392-415.
Thompson, V. A. (1965), Bureaucracy and Innovation, Administrative Science Quarterly, 5, s. 1-20.

Tolbert, P. S., ve Zucker, L. G. (1983), Institutional Sources of Change in the Formal Structure of Organizations: The Diffusion of Civil Service Reform, 18801935, Administrative Science Quarterly, 28:1, s. 22-39.

Trice, H., ve Morand, D. (1991), Organisational Subculture and Countercultures. In G. Miller (Ed.), Studies in Organisational Sociology ( s. 45-69). Greenwich, CT: JAI Press.

Trott, P. (1998). Innovation Management and New Product Development, London: Pitman Publishing.

Tseng, Y. F. ve Lee, T. Z. (2009), Comparing Appropriate Decision Support of Human Resource Practices on Organizational Performance with DEA/AHP model, Expert Systems with Applications, 36, s. 6548-6558.

Urban, G. L., Weinberg, B. D. ve Hauser, J. R. (1996). Premarket Forecasting of Really-New Products. Journal of Marketing, 47-60.

Van de Ven, A. H. (1986), Central Problems in the Management of Innovation. Management Science, 32, s. 509-607.

Van de Ven, A.H., Angle, H. ve Poole, M.S. (1989), Research on the Management of Innovation, Cambridge, MA: Ballinger.

Vos, J. P. (2004), Developing Strategic SelfDescription of SMEs. Technovation, 25, s. 989-999.

Wallach, E. (1983), Individuals and Organization: The Cultural Match. Training and Development Journal, 12, s. 28-36.

Wang, D. S. ve Shyu, C. L. (2003), The Impact 
of Organizational Culture and Knowledge Sharing Motivation on Knowledge Sharing, Sun Yat-Sen Management Review, 11:3, s. 409-431.

Wang, G. ve Netemeyer, R. G. (2002), The Effects of Job Autonomy, Customer Demandingness, and Trait Competitiveness on Salesperson Learning, Self-Efficacy, and Performance, Journal of The Academy of Marketing Science, 30:3, s. 217-228.

Warren, J. ve Johnson, P. (1995), The Impact of Workplace Support on Work-Family Role Strain, Family Relations 44, s. 16369.

West, M. A. ve Farr, J. L. (1989), Innovation at Work: Psychological Perspectives, Social Behavior, 4, s. 15-30.

West, M. A. ve Farr, J. L. (1990). Innovation at work. In M. A. West \& J. L. Farr (ed.), Innovation and Creativity at Work (s. 313). Chichester: John Wileys.

West, M. A., Borrill, C., Dawson, J., Brodbeck, F., Shapiro, D. ve Haward, B. (2003), Leadership Clarity and Team Innovation in Health Care, Leadership Quarterly, 14, s. 393-410.

Wiener, Y. ve Vardi, Y. (1990), Relationship Between Organizational Culture and Individual Motivation: A Conceptual Integration, Psychological Reports, 67, s. 295-306.

Woodman, R. W., Sawyer, J. E., ve Griffin, R. W. (1993), Toward a Theory of Organizational Creativity, Academy of Management Review, 18:2, s. 293-321.

Yuan, F. ve R. W. Woodman (2010), Innovatıve Behavior in The Workplace: The Role of Performance and Image Outcome Expectations, Academy of Management Journal, 53:2, s. 323-342.
Zahra, S.A. (1993), Environment, Corporate

Entrepreneurship and Financial Perfor-

mance: A Taxonomic Approach, Jour-

nal of Business Venturing, 8:4, s. 319-40.

Zhou, J. (2003), When The Presence of Crea-

tive Coworkers is Related to Creativity:

Role of Supervisor Close Monitoring,

Developmental Feedback, and Creative

Personality, Journal of Applied Psycho-

$\log y, 88$, s. 413-422. 
114 "ISS, GÜC̣" Endüstrii illișkileri ve Insan Kaynakları Dergisi

Ekim/October 2011 - Cilt/Vol: 13 - Sayı/Num: 04 